\title{
The remarkably strong Arctic stratospheric polar vortex of Winter 2020: links to record-breaking arctic oscillation and ozone loss
}

Article

Accepted Version

Lawrence, Z. D., Perlwitz, J., Butler, A. H., Manney, G. L., Newman, P. A., Lee, S. H. and Nash, E. R. (2020) The remarkably strong Arctic stratospheric polar vortex of Winter 2020: links to record-breaking arctic oscillation and ozone loss. Journal of Geophysical Research: Atmospheres, 125 (22). e2020JD033271. ISSN 2169-8996 doi: https://doi.org/10.1029/2020JD033271 Available at https://centaur.reading.ac.uk/93447/

It is advisable to refer to the publisher's version if you intend to cite from the work. See Guidance on citing.

To link to this article DOI: http://dx.doi.org/10.1029/2020JD033271

Publisher: American Geophysical Union

All outputs in CentAUR are protected by Intellectual Property Rights law, including copyright law. Copyright and IPR is retained by the creators or other copyright holders. Terms and conditions for use of this material are defined in the End User Agreement. 


\section{www.reading.ac.uk/centaur}

\section{CentAUR}

Central Archive at the University of Reading

Reading's research outputs online 


\title{
The Remarkably Strong Arctic Stratospheric Polar Vortex of Winter 2020: Links to Record-Breaking Arctic Oscillation and Ozone Loss
}

\author{
Zachary D. Lawrence ${ }^{1,2}$, Judith Perlwitz ${ }^{2}$, Amy H. Butler ${ }^{3}$, Gloria L.
} Manney ${ }^{4,5}$, Paul A. Newman ${ }^{6}$, Simon H. Lee ${ }^{7}$, Eric R. Nash ${ }^{6,8}$

${ }^{1}$ Cooperative Institute for Research in Environmental Sciences (CIRES), University of Colorado, Boulder, Colorado, USA

${ }^{2}$ NOAA Physical Sciences Laboratory (PSL), Boulder, Colorado, USA ${ }^{3}$ NOAA Chemical Sciences Laboratory (CSL), Boulder, Colorado, USA

${ }^{4}$ NorthWest Research Associates (NWRA), Socorro, New Mexico, USA ${ }^{5}$ New Mexico Tech (NMT), Socorro, New Mexico, USA

${ }^{6}$ NASA, Goddard Space Flight Center (GSFC), Greenbelt, Maryland, USA

${ }^{7}$ Department of Meteorology, University of Reading, Reading, UK

${ }^{8}$ Science Systems and Applications, Inc. (SSAI), Lanham, Maryland, USA

Key Points:

- The Arctic stratospheric polar vortex during the 2019/2020 winter was the strongest and most persistently cold in over 40 years

- Low tropospheric planetary wave driving and a wave-reflecting configuration of the stratosphere supported the strong and cold polar vortex

- Seasonal records in the Arctic Oscillation and stratospheric ozone loss were related to the strong polar vortex

Corresponding author: Zachary Lawrence, zachary.lawrence@noaa.gov 


\begin{abstract}
The Northern Hemisphere (NH) polar winter stratosphere of 2019/2020 featured an exceptionally strong and cold stratospheric polar vortex. Wave activity from the troposphere during December-February was unusually low, which allowed the polar vortex to remain relatively undisturbed. Several transient wave pulses nonetheless served to help create a reflective configuration of the stratospheric circulation by disturbing the vortex in the upper stratosphere. Subsequently, multiple downward wave coupling events took place, which aided in dynamically cooling and strengthening the polar vortex. The persistent strength of the stratospheric polar vortex was accompanied by an unprecedentedly positive phase of the Arctic Oscillation in the troposphere during January-March, which was consistent with large portions of observed surface temperature and precipitation anomalies during the season. Similarly, conditions within the strong polar vortex were ripe for allowing substantial ozone loss: The undisturbed vortex was a strong transport barrier, and temperatures were low enough to form polar stratospheric clouds for over four months into late March. Total column ozone amounts in the NH polar cap decreased, and were the lowest ever observed in the February-April period. The unique confluence of conditions and multiple broken records makes the 2019/2020 winter and early spring a particularly extreme example of two-way coupling between the troposphere and stratosphere.
\end{abstract}

\title{
Plain Language Summary
}

Wintertime westerly winds in the polar stratosphere (from $\sim 15-50 \mathrm{~km}$ ), known as the stratospheric polar vortex, were extraordinarily strong during the Northern Hemisphere winter of $2019 / 2020$. The exceptional strength of the stratospheric polar vortex had consequences for winter and early spring weather near the surface, and for stratospheric ozone depletion. Typically atmospheric waves generated in the troposphere spread outward and upward into the stratosphere where they can disturb and weaken the polar vortex, but tropospheric wave activity was unusually weak during the 2019/2020 winter. In addition, an unusual configuration of the stratospheric polar vortex developed that reflected waves traveling upward from the troposphere back downward. These unique conditions allowed the vortex to remain strong and cold for several months. During JanuaryMarch 2020, the strong stratospheric polar vortex was closely linked to a near-surface circulation pattern that resembles the positive phase of the so-called "Arctic Oscillation" (AO). This positive AO pattern was also of record strength, and influenced the regional distributions of temperatures and precipitation during the late winter and early spring. Cold and stable conditions within the polar vortex also allowed strong ozone depletion to take place, leading to lower ozone levels than ever before seen above the Arctic in spring.

\section{Introduction}

The Northern Hemisphere (NH) late winter and spring of 2020 featured a series of remarkable climate extremes. The tropospheric Arctic Oscillation - the dominant pattern of extratropical climate variability that describes the latitudinal shift of the eddydriven jet stream (AO; Thompson \& Wallace, 1998) - was effectively locked in a highly positive phase for several months. Stratospheric ozone in the polar cap fell to low levels never before observed in early NH spring. These phenomena were connected by the Arctic stratospheric polar vortex, which was unusually and persistently strong and cold during the season. This paper provides an overview of the 2019/2020 record breaking strong stratospheric polar vortex event and its connections to the extremes in the tropospheric $\mathrm{AO}$ and Arctic ozone.

During $\mathrm{NH}$ winter, the stratospheric and tropospheric circulations are closely connected. The principal circulation feature of the polar wintertime stratosphere is the stratospheric polar vortex (hereinafter, the polar vortex), which consists of a strong westerly circulation spanning from roughly $100 \mathrm{hPa}$ to above $1 \mathrm{hPa}$ (Waugh et al., 2017). Dur- 
ing the winter polar night, the polar vortex strengthens and cools via radiative cooling. However, the strength of the polar vortex is also modulated by dynamical tropospherestratosphere coupling via planetary scale waves generated in the troposphere from orography and sources of diabatic heating (e.g., Charney \& Drazin, 1961; Matsuno, 1970). Waves from the troposphere can propagate vertically into the polar stratosphere, where they can break and disturb the polar vortex. Breaking waves deposit easterly momentum, which weakens the westerly zonal circulation represented by the polar vortex, and warms the polar stratosphere. Thus, the average strength of the polar vortex over a season closely depends on the time-integrated wave driving of the stratosphere; for example, below average wave driving supports the development of a strong polar vortex, since uninterrupted radiative cooling allows the vortex to more closely approach the very cold conditions of radiative equilibrium.

Internal stratospheric processes can also influence polar vortex strength. Since wave propagation characteristics are determined by the basic state flow, the interplay between dynamic driving and radiative relaxation can alter the action of waves on the stratospheric circulation. For example, downward wave coupling events in which upward propagating waves are reflected back from the stratosphere to the troposphere dynamically strengthen and cool the vortex by weakening or reversing the residual circulation (Shaw \& Perlwitz, 2014; Dunn-Sigouin \& Shaw, 2015). These events have been shown to be preceded by transient pulses of upward wave activity that help develop reflective configurations of the polar stratospheric circulation (Harnik, 2009; Shaw et al., 2010; Shaw \& Perlwitz, 2013; Dunn-Sigouin \& Shaw, 2018). Winters with more frequent downward wave coupling events generally correspond to winters with stronger polar vortices in the lower and middle stratosphere (Perlwitz \& Harnik, 2003).

The interannual variability in the strength of the Arctic polar vortex is quite large. Sudden stratospheric warmings (SSWs) are relatively common in the $\mathrm{NH}$, occurring in roughly 6 out of 10 years (Butler et al., 2017); these events involve an extreme mid-winter weakening of the polar vortex that is generally driven by enhanced wave driving. Since SSWs often lead to a nearly complete breakdown of the polar vortex, and the timescale of recovery from a weak stratospheric circulation can be long (Hitchcock \& Shepherd, 2013; Hitchcock et al., 2013), SSWs generally correspond to persistent weak polar vortex events. In contrast, persistent strong vortex events like that observed during the winter and spring of 2020 are quite rare in comparison to SSWs. Because of the relatively short timescales on which planetary wave driving acts, the polar vortex can rapidly shift from a strong state to a neutral or weak state (Limpasuvan et al., 2005; Lawrence \& Manney, 2018). Maintaining a strong polar vortex for long periods of time thus requires unique conditions, such as weak upward wave activity and/or enhanced downward wave activity.

The strength of the NH polar vortex is generally recognized as an important element for coupling between the stratosphere and troposphere on sub-seasonal to seasonal timescales during winter and spring (e.g., Kidston et al., 2015; Butler et al., 2019). A main expression of two-way stratosphere-troposphere dynamical coupling during NH winter is the close statistical relationship between the strength of the stratospheric polar vortex and the phase of the tropospheric AO (e.g., Baldwin \& Dunkerton, 2001; Kidston et al., 2015). These relationships are commonly expressed using metrics that describe phases of the "Northern Annular Mode" (NAM), a pattern that characterizes meridional shifts of mass into or out of the polar cap throughout the atmospheric column (note that the NAM and AO are often used interchangeably; Thompson \& Wallace, 2000; Baldwin, 2001). Anomalously strong or weak polar vortex states correspond to positive or negative phases of the stratospheric NAM, respectively, and these tend to be followed in the troposphere by positive or negative AO events, which may last for weeks to months and alter patterns of surface temperatures and precipitation (Baldwin \& Dunkerton, 2001; Polvani \& Kushner, 2002; Limpasuvan et al., 2005; Dunn-Sigouin \& Shaw, 2015; Kid- 
ston et al., 2015; Tripathi, Charlton-Perez, et al., 2015; Orsolini et al., 2018; Domeisen, 2019; King et al., 2019). Downward wave coupling events can not only strengthen the polar vortex, but also directly induce tropospheric circulation patterns consistent with a positive AO on short timescales (Shaw \& Perlwitz, 2013; Dunn-Sigouin \& Shaw, 2015). However, phases of the tropospheric AO/NAM do not always consistently follow the strength of the polar vortex. Factors that seem to determine whether a given vortex event will influence the troposphere include the persistence and magnitude of stratospheric anomalies, the depth to which anomalies penetrate into the lower stratosphere, and the tropospheric state at the time of the stratospheric event (Kodera et al., 2016; Karpechko et al., 2017; Charlton-Perez et al., 2018; Domeisen, 2019; White et al., 2019; Rao et al., 2020).

The conditions that determine the potential for chemical ozone destruction in the $\mathrm{NH}$ stratosphere also tie in to polar vortex strength, albeit in subtle ways that are highly sensitive to meteorology (WMO, 2014, 2018). Chlorine and bromine trace gases, primarily from anthropogenic sources, are converted from reservoir (non-ozone depleting) forms to reactive (ozone-depleting) forms on the surfaces of polar stratospheric clouds (PSCs; e.g., Solomon, 1999), which require very low temperatures ( 195 K) to form in the lower stratosphere. Activation of chlorine/bromine also generally requires persistent confinement with cold air inside the polar vortex so that mixing with low latitude air cannot dilute the "activated air" (Schoeberl \& Hartmann, 1991; Schoeberl et al., 1992). The chemical reactions that destroy ozone further require sunlight exposure, such that chemical ozone loss tends to dominate when sunlight returns to the polar regions in early spring, a time when, climatologically, the Arctic vortex is often very weak or broken down altogether (Black et al., 2006; Lawrence et al., 2018). The aforementioned conditions for ozone destruction are typically only present when the polar vortex is strong, cold, and stable, but the interannual variability in the Arctic polar vortex is so large that individual seasons can have individual conditions present without the others: For example, the polar vortex in 2015/2016 was persistently strong and cold for much of the season, but a dynamically driven early final warming occurred in the beginning of March, which cut short the chemical ozone loss, and broke down the vortex (Manney \& Lawrence, 2016), preventing an extreme ozone deficit. Downward wave coupling events in the stratosphere encourage chemical ozone loss through dynamically cooling and strengthening the polar vortex; they also reduce the downward resupply of ozone through their ability to weaken and/or reverse the residual circulation (Shaw \& Perlwitz, 2014; Lubis et al., 2017).

In this paper we will show that the 2019/2020 record breaking strong vortex developed in the wake of a combination of low wave driving from the troposphere and multiple downward wave coupling events that occurred following formation of a reflective configuration in the upper stratospheric circulation. The record-breaking strength of the vortex was accompanied by a record-breaking positive phase of the tropospheric AO that lasted several months and was related to large fractions of $\mathrm{NH}$ seasonal surface temperatures and precipitation anomalies. We will further illustrate that the strong and stable vortex also provided conditions that were ideal for chemical ozone loss to take place, resulting in the lowest Arctic ozone amounts on record during late winter and early spring. That the record-breaking $\mathrm{AO}$ and low ozone events took place individually is notable, but that they both occurred during the same season makes the 2019/2020 Arctic winter particularly extraordinary.

The rest of the paper is organized as follows: Section 2 outlines the datasets and methods we use. Section 3 is broken into subsections that focus on describing the record strength of the vortex (Section 3.1); the coupled troposphere-stratosphere evolution (Section 3.2); the influence of two-way wave coupling on the vortex (Section 3.3); and the vortex conditions that were conducive for ozone loss (Section 3.4). In Section 4, we briefly discuss our results in the context of previous winters, and provide some research questions that are motivated by this record-breaking winter and early spring. Finally, in Section 5 we summarize our results. 


\section{Data and Methods}

We combine data from multiple sources to analyze the conditions during the $2019 / 2020$ Arctic winter, and to provide historical context from previous winters. Meteorological variables such as temperatures, winds, and geopotential height are from the National Aeronautics and Space Administration (NASA) Modern-Era Retrospective analysis for Research and Applications version 2 (MERRA-2; Gelaro et al., 2017). We specifically use daily mean fields from the pressure ("M2I3NPASM"; GMAO, 2020b) and model ("M2I3NVASM" GMAO, 2020a) level collections. For historical context of stratospheric zonal mean zonal winds from previous winters, we also utilize daily mean pressure level data from the Japanese Meteorological Agency's 55-year reanalysis (JRA-55; Kobayashi et al., 2015) for winter seasons from 1958/1959 to 1978/1979. Ozone data and statistics are compiled from multiple satellite instruments, but are primarily from the Ozone Mapping and Profiling Suite (OMPS) from data made available via the NASA OzoneWatch resource (see, e.g., https://ozonewatch.gsfc.nasa.gov/data/ and https://ozonewatch.gsfc.nasa.gov/ meteorology/figures/ozone/); missing column ozone values in polar night are filled using MERRA-2 data. Daily values for the Arctic Oscillation index are provided by the National Centers for Environmental Prediction (NCEP) Climate Prediction Center (CPC) at https://www.cpc.ncep.noaa.gov/products/precip/CWlink/daily_ao_index/ao .shtml; we refer to these data as the $\mathrm{AO}_{C P C}$.

We use diagnostics based on the Transformed Eulerian Mean (TEM) framework (Andrews et al., 1987), including Eliassen-Palm fluxes and residual velocities to describe the wave driving conditions and evolution of the stratospheric circulation during the 2019/2020 winter season. We calculate these diagnostics based on the primitive equation formulation (see, e.g., Martineau et al., 2018) using MERRA-2 pressure level fields. We also use diagnostics of polar processing, which describe the development and maintenance of conditions that support chemical ozone loss; we compute these as described in Lawrence et al. (2018) using daily mean MERRA-2 data. Briefly, we use isentropic potential vorticity $(\mathrm{PV})$ to determine the size of the polar vortex and the magnitude of PV gradients at the vortex edge, characteristics that assess the polar vortex as a transport barrier. We also use temperatures to determine whether conditions support the development of PSCs, and the size of regions able to form PSCs. We specifically express the size of regions cold enough to form nitric acid trihydrate (NAT) PSCs as the volume of cold air divided by the volume of the vortex $\left(V_{N A T} / V_{\text {vort }}\right)$, where the volumes span only the lower stratosphere (see Lawrence et al., 2018, for details).

Unless otherwise noted, we calculate anomalies with respect to climatologies using the full records available, but excluding 2020. Similarly, we use cosine-latitude weighted averages to calculate quantities representative of a range of latitudes. Note that the NAM and AO refer to identical phenomena (Baldwin, 2001; Baldwin \& Dunkerton, 2001), but herein we use the NAM to refer to the vertically resolved profile of mass fluctuations in the $\mathrm{NH}$ extratropical circulation, and the AO to refer to the near-surface pattern. We calculate the vertically resolved NAM index using standardized $65-90^{\circ} \mathrm{N}$ geopotential height anomalies as motivated by Cohen et al. (2002) and Baldwin and Thompson (2009), multiplied by -1 for consistent phasing with the AO.

\section{Results}

\subsection{Strength of the 2019/2020 Polar Vortex in Context}

In the middle stratosphere, zonal mean zonal winds were above average between $55-75^{\circ} \mathrm{N}$ for the majority of the extended winter season, but became particularly strong around mid-January (Figure 1a). Beginning in January, polar vortex winds were regularly more than $20 \mathrm{~m} / \mathrm{s}$ higher than those in the climatology. In February, the wind anomalies exceeded two standard deviations of the November-April climatology for over a full 
month and reached record maxima during a period of time in the seasonal cycle when winds in this altitude and latitude region generally decrease.

The temporal evolution of zonal wind anomalies at $60^{\circ} \mathrm{N}$ as a function of pressure reveals that the vortex was generally stronger than normal in the stratosphere between 100 and $1 \mathrm{hPa}$ from November to April (Fig 1b). The only exception is a short-lived vortex disturbance from mid-November to early December, as evidenced by negative wind anomalies between about 30 and $1 \mathrm{hPa}$ at this time. Winds in the troposphere became anomalously positive for a brief period in early December, while more consistent positive anomalies that often reached more than $10 \mathrm{~m} / \mathrm{s}$ above normal became established in January.

Also notable is the zonal wind evolution in the upper stratosphere and lower mesosphere (USLM; approximately pressures lower than $1 \mathrm{hPa}$ ). Following the short lived stratospheric vortex disturbance in mid-November, winds in the USLM accelerated and briefly became very strong, reaching record high values and exceeding 2 standard deviations for a short time in mid-December. However, beginning in January, there is a clear contrast between winds in the USLM and the stratosphere; those in the USLM were generally weaker than normal, while those in the stratosphere proper were generally stronger than normal, and reached record strength for periods in February and March.

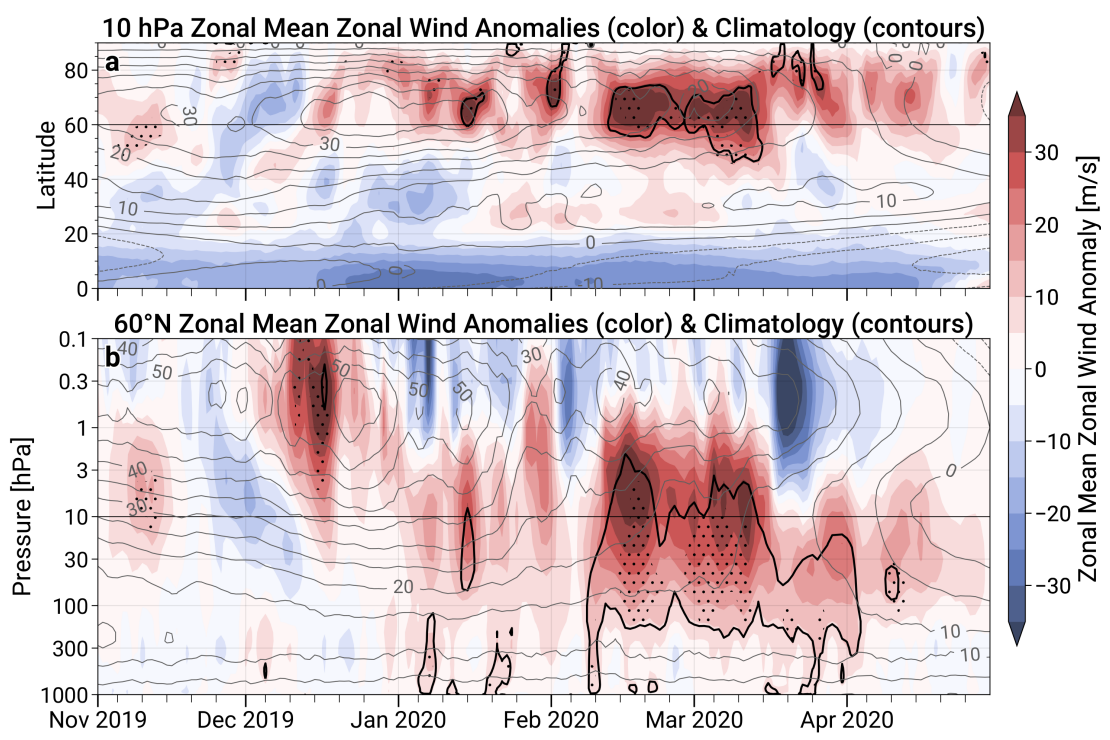

Figure 1. Time series of zonal mean zonal wind anomalies as a function of latitude at $10 \mathrm{hPa}$ (a), and at $60^{\circ} \mathrm{N}$ as a function of pressure (b). The grey line contours represent the climatology; the black lines enclose the times when anomalies exceed +2 standard deviations of the NovemberApril daily climatology; and stippling indicates when the zonal wind values were maxima in the MERRA-2 record.

The stratospheric circulation was clearly stronger than normal for almost the entirety of the extended December-March (DJFM) winter season. A comparison of zonal mean zonal winds across other winter seasons reveals that the polar vortex in 2020 was the strongest on record at 10 and $100 \mathrm{hPa}$ for seasons back to 1979/1980 (Figure 2). This era is typically considered to be the "satellite-era"; when also including prior years back to $1958 / 1959$ for which reanalysis data are more uncertain because of the relative lack of observations to constrain the reanalysis (see discussion in Hitchcock, 2019), the 2020 
zonal winds at $10 \mathrm{hPa}$ rank third across all available years, only exceeded by 1966/1967 and 1975/1976. At $100 \mathrm{hPa}$, the 2019/2020 zonal winds are the largest on record even when taking into account these earlier years. We note that in the post-1980 era, the differences in the seasonal zonal winds between MERRA-2 and JRA-55 are very small; the absolute maximum differences in the DJFM means are $0.6 \mathrm{~m} / \mathrm{s}$ and $1.0 \mathrm{~m} / \mathrm{s}$ at 10 and $100 \mathrm{hPa}$, respectively, indicating that these results are robust between these two reanalysis data sets. These results also demonstrate that the rankings for seasonal strength of the polar vortex in the middle stratosphere do not always correspond to those in the lowermost stratosphere. For example, the years that follow 2019/2020 in ranking for seasonally strong polar vortices at $10 \mathrm{hPa}$ such as 1995/1996, 1996/1997, and 2010/2011 have values at $100 \mathrm{hPa}$ that are exceeded by other years such as 1989/1990 and 1992/1993.

\section{DJFM Zonal Mean Zonal Winds at $60^{\circ} \mathrm{N}$}

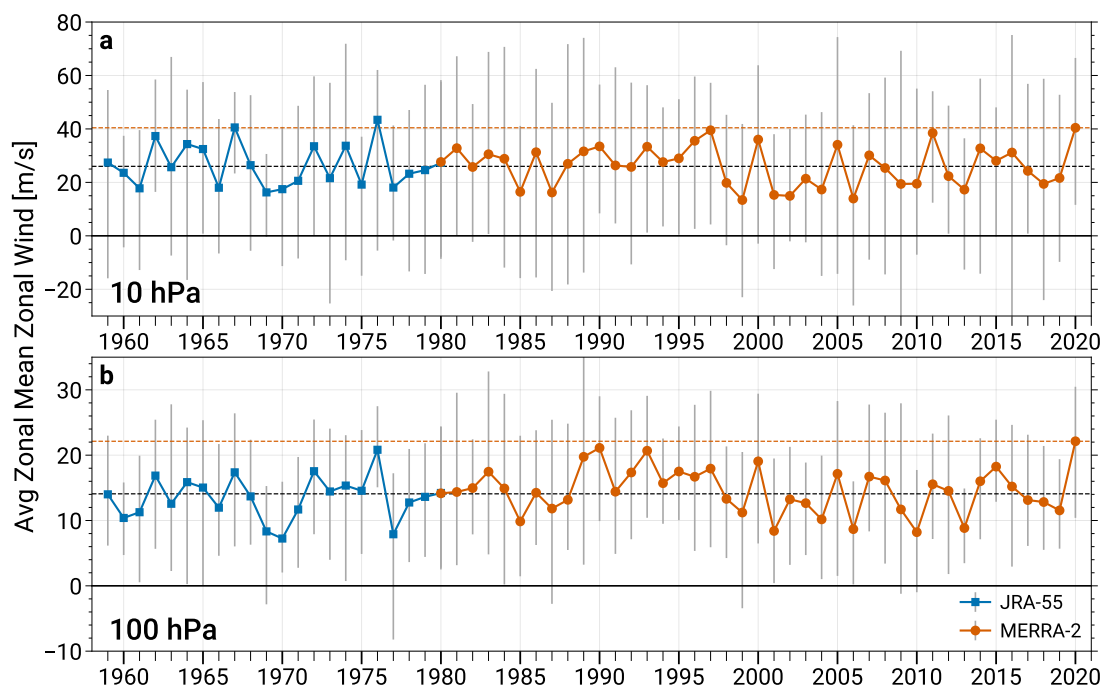

Figure 2. Yearly time series of the December-March averaged zonal mean zonal winds at $60^{\circ} \mathrm{N}$, at 10 (a) and 100 (b) hPa. The blue lines and squares represent values determined from the JRA-55 reanalysis for 1959 through 1979; the orange lines and circles represent the values determined from MERRA-2. The grey whiskers in each panel represent the range of the daily mean zonal wind values during each season.

\subsection{An Extreme Event of the Coupled Troposphere-Stratosphere An- nular Mode}

The 2020 strong vortex event that developed in January and lasted through March was vertically coherent throughout the depth of the stratosphere. Moreover, the positive zonal wind anomalies in the troposphere during this time indicate that the zonal pattern also extended into the troposphere (Figure 1). Figures 3a and b show the coherent evolution of stratospheric and tropospheric circulation anomalies characterized by indices of the NAM and AO, which clearly illustrate a positive NAM/AO state between 1000 and $1 \mathrm{hPa}$ for almost the entire three months of January-March (JFM).

We use two diagnostics to illustrate how unusual this winter was with respect to the coupled stratosphere-troposphere NAM behaviour. First, we assess the influence of wave driving on the stratospheric polar vortex. Newman et al. (2001) showed that early spring polar stratospheric temperatures are highly correlated with time integrated eddy 
heat fluxes, revealing that interannual variability in spring polar stratospheric temperatures is tied to the integrated amount of wave driving supplied by the troposphere and entering the stratosphere. Similarly, Polvani and Waugh (2004) showed a robust anticorrelation between time integrated eddy heat fluxes and the stratospheric NAM, further indicating a control on the vortex strength by wave driving. Figure $3 \mathrm{c}$ supplements these relationships by displaying a scatterplot of the $100 \mathrm{hPa} 40-80^{\circ} \mathrm{N}$ vertical component of the Eliassen-Palm (EP) flux $\left(\mathrm{F}_{z}\right.$; a diagnostic of vertical wave propagation) averaged over DJF versus the $50 \mathrm{hPa}$ NAM averaged over JFM, which confirms a very close relationship $(\mathrm{r}=-0.8)$. Moreover, Figure 3c clearly illustrates that the 2020 winter season represents a new extreme, with both the lowest DJF upward wave activity at 100 $\mathrm{hPa}$ and the strongest $50 \mathrm{hPa} \mathrm{NAM}$ event in the MERRA-2 record.

Second, we put the 2020 coherent stratospheric and tropospheric NAM/AO behavior into context with previous years. Prior studies have shown that there is a significant statistical relationship between the strength of the stratospheric polar vortex (stratospheric NAM) and the AO on seasonal timescales (e.g., Thompson \& Wallace, 1998). Figure 3d demonstrates this relationship as a scatterplot of JFM values of the $50 \mathrm{hPa}$ NAM versus polar cap sea level pressure (SLP). The correlation is approximately -0.68 , and is statistically significant at the $99 \%$ level following a bootstrap test of 50000 resamples. The JFM season of 2020 particularly stands out as the most extreme year in the MERRA2 record, involving extremes in both the stratospheric NAM and negative sea level pressure anomalies. While this result does not imply a clear direction of influence or causality, it is obvious from Figure 3a that the stratospheric anomalies were persistent, of large magnitude, and reached into the lower stratosphere. Similarly, a positive AO developed slightly before or simultaneous with the stratospheric anomalies in late December and early January, meaning that the tropospheric anomalies either developed in concert with the stratosphere, or was in a favorable state for coupling with a positive stratospheric NAM.

While we have shown that the 2020 JFM NAM index was consistent with extremely low upward wave activity at $100 \mathrm{hPa}$ (Fig 3c), the $100 \mathrm{hPa}$ level is generally representative of the lower stratosphere, and thus upward wave activity at this level is not necessarily indicative of wave activity from the troposphere (e.g., see discussion in de la Cámara et al., 2017). Figure 4 shows the yearly DJF mean $\mathrm{F}_{z}$ at $300 \mathrm{hPa}$ in the upper troposphere versus $100 \mathrm{hPa}$ as a scatterplot. These are positively correlated, but only modestly so $(\mathrm{r}=0.46)$, indicating that the amount of wave activity in the upper troposphere is not a perfect predictor of that for the lower stratosphere on seasonal timescales. Nonetheless, 2019/2020 stands out among the other years as being the most coherent extreme minimum in DJF $\mathrm{F}_{z}$ at both 100 and $300 \mathrm{hPa}$. This result ties back to the NAM and SLP relationships illustrated in Figure 3, indicating that on average low upward wave driving of the stratosphere by the troposphere likely played a role in the development of the strong polar vortex in JFM (Fig 3c), and subsequently the negative polar cap SLP anomalies (Fig 3d).

At the surface, extratropical SLP anomalies were consistent with the long-lived positive $\mathrm{AO}$ and strong stratospheric polar vortex (Fig 3a,b,d). Figure 5a shows that the SLP anomalies throughout JFM were primarily characterized by an annular pattern of anomalously low pressure in the polar cap, surrounded by a ring of anomalously high pressure in mid-latitudes, which closely resembles the canonical AO pattern. Figure 5b illustrates the $2020 \mathrm{JFM}$ mean $\mathrm{AO}_{C P C}$ index was the highest on record since 1950 with a value of $\sim 2.7$. Moreover, the persistence of this positive $\mathrm{AO}$ event was unprecedented; the minimum and maximum daily $\mathrm{AO}_{C P C}$ index values during JFM 2020 were both the highest on record, and values were consecutively above 1 for 56 days, greater than any previous year shown (Fig 5c). The JFM seasons of 1988/1989 and 1989/1990 also featured large and persistently positive $\mathrm{AO}$ events; both of these years also featured polar 


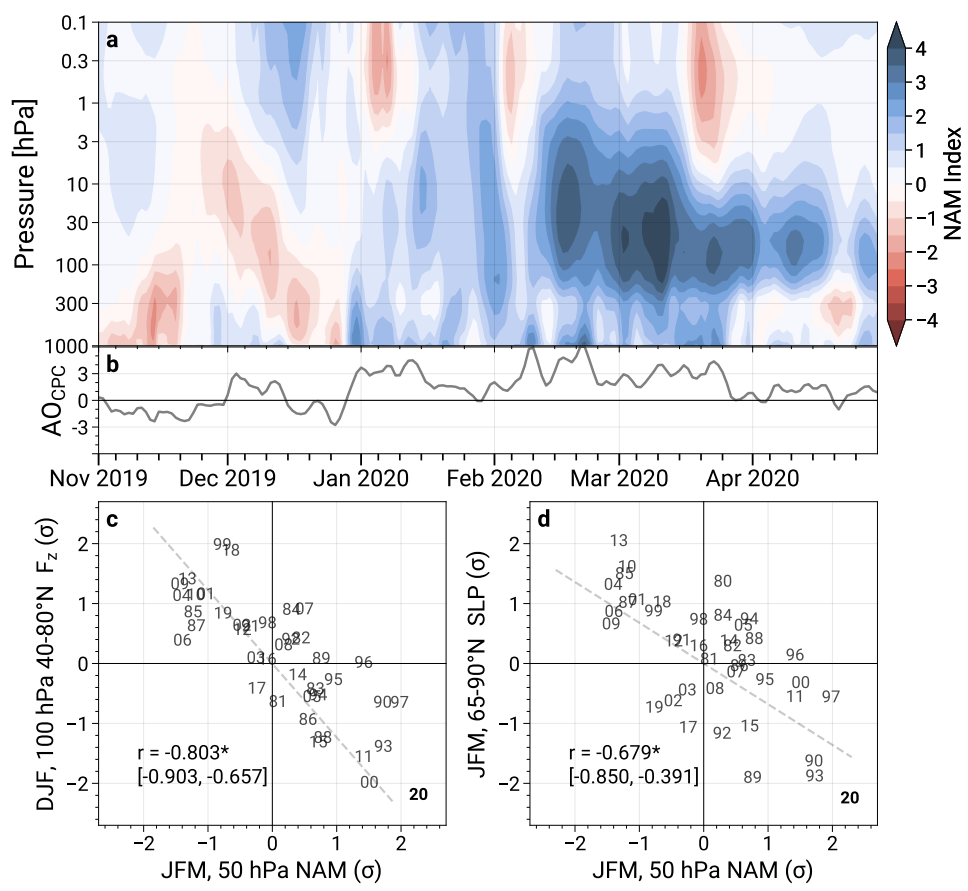

Figure 3. Time series of the Northern Annular Mode (a) and CPC Arctic Oscillation (b) indices from November 2019 through April 2020. Also shown are scatterplots of DecemberFebruary (DJF) $100 \mathrm{hPa} 40-80^{\circ} \mathrm{N}$ averaged vertical component of the Eliassen-Palm Flux $\left(\mathrm{F}_{z}\right)$ versus the JFM $50 \mathrm{hPa}$ NAM index (c), and the JFM $50 \mathrm{hPa}$ NAM index versus $65-90^{\circ} \mathrm{N}$ sea level pressure (d). All quantities in the scatter plots are standardized with respect to the yearly seasons. Correlations are indicated in the bottom left of panels c and d above $99 \%$ bootstrap confidence intervals from 50000 resamples.

vortices of above average seasonal strength in the lower stratosphere (particularly 1989/1990; see Figures $2 \mathrm{~b}$ and $3 \mathrm{~d}$ ).

The extreme positive AO event that occurred during JFM 2020 explains a substantial fraction of the observed surface temperature and precipitation anomalies, including record warmth that occurred in Eurasia. Figure 6 compares the observed seasonal patterns of surface temperature and precipitation anomalies with those that are congruent with the $\mathrm{AO}$, determined from multiplying the $2020 \mathrm{JFM} \mathrm{AO}_{C P C}$ value with the regression map of these quantities onto the JFM $\mathrm{AO}_{C P C}$ historical time series. Surface temperatures were primarily characterized by very anomalous warmth in Eurasia, and cold in Canada, Greenland, and Alaska (Fig 6a). The Eurasian warmth (from 0-135 ${ }^{\circ} \mathrm{E}, 45-$ $75^{\circ} \mathrm{N}$ ) was unprecedented in the MERRA-2 record back to 1980 (not shown). Precipitation was largely above normal in bands along Northern Europe, central Siberia, and southern Eurasia (Fig 6d). The patterns congruent with the AO are generally consistent with that observed, but typically of lesser amplitude (e.g., the underestimation of temperatures over Eurasia; Fig 6b,e). Zonal means of the observed and AO-congruent anomalies (Fig 6c,f) highlight rough estimates of the fractions of patterns attributable to the AO. Between 40 and $70^{\circ} \mathrm{N}$, the JFM AO explains about $2 / 3$ of the amplitude of temperature anomalies, with a residual of about $0.5 \mathrm{~K}$. The AO explains virtually all of the zonal mean precipitation anomalies between roughly $55-70^{\circ} \mathrm{N}$, but overestimates the dry band along approximately $40^{\circ} \mathrm{N}$. We note these quantities are not detrended, and 


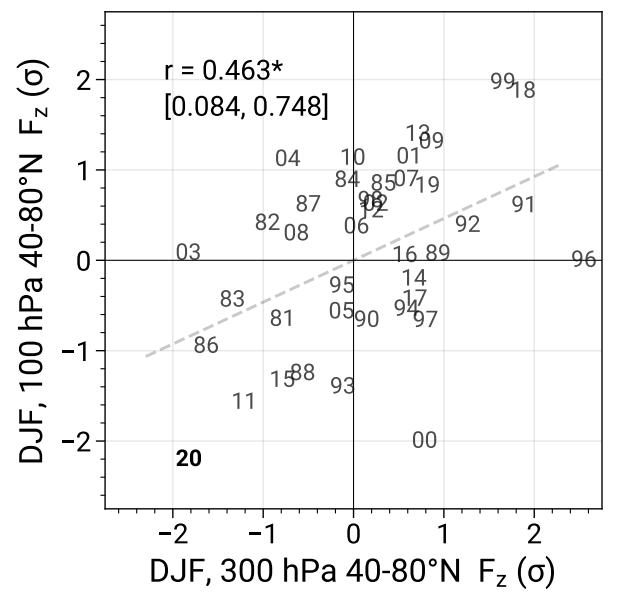

Figure 4. Scatterplot of the December-February (DJF) mean of the $40-80^{\circ} \mathrm{N}$ averaged vertical component of the EP-flux $\left(\mathrm{F}_{z}\right)$ at $300 \mathrm{hPa}$ versuss $100 \mathrm{hPa}$. The values shown are standardized with respect to the yearly seasons. The year labels are for the January of each season. The correlation is indicated in the top left above $99 \%$ bootstrap confidence intervals from 50000 resamples.
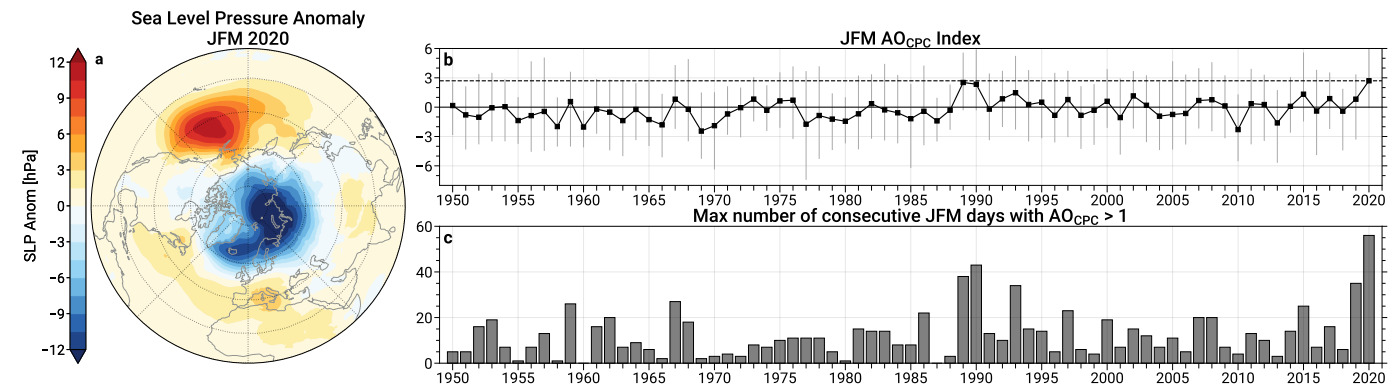

Figure 5. Map of Northern Hemisphere sea level pressure anomalies averaged over JanuaryMarch (JFM) 2020 (a), yearly time time series of the JFM mean CPC AO index (b), and yearly time series of the max number of consecutive JFM days in which the CPC AO index exceeded 1 (c). The whiskers in panel b represent the range of the AO values during the respective JFM seasons; the black dashed horizontal line is plotted at the mean value for 2020 .

thus some of the observed patterns (such as the Eurasian warmth) may also be attributable to climate change warming.

\subsection{Wave Driving and Reflection: Dynamic Control of Polar Vortex Strength}

The previous subsection clearly illustrated the unusual conditions of the coupled stratosphere-troposphere system over the 2019/2020 winter season. Now we will describe in more detail the processes that led to the development of such a strong polar vortex by focusing more closely on the wave driving conditions.

The occurrence of the extremely strong stratospheric polar vortex of 2020 can be partly understood though a closer examination of the evolution of tropospheric wave driving throughout the season (Figure 7). In general, waves in the troposphere that linearly interfere in a constructive/destructive way with the climatological stationary wave pat- 

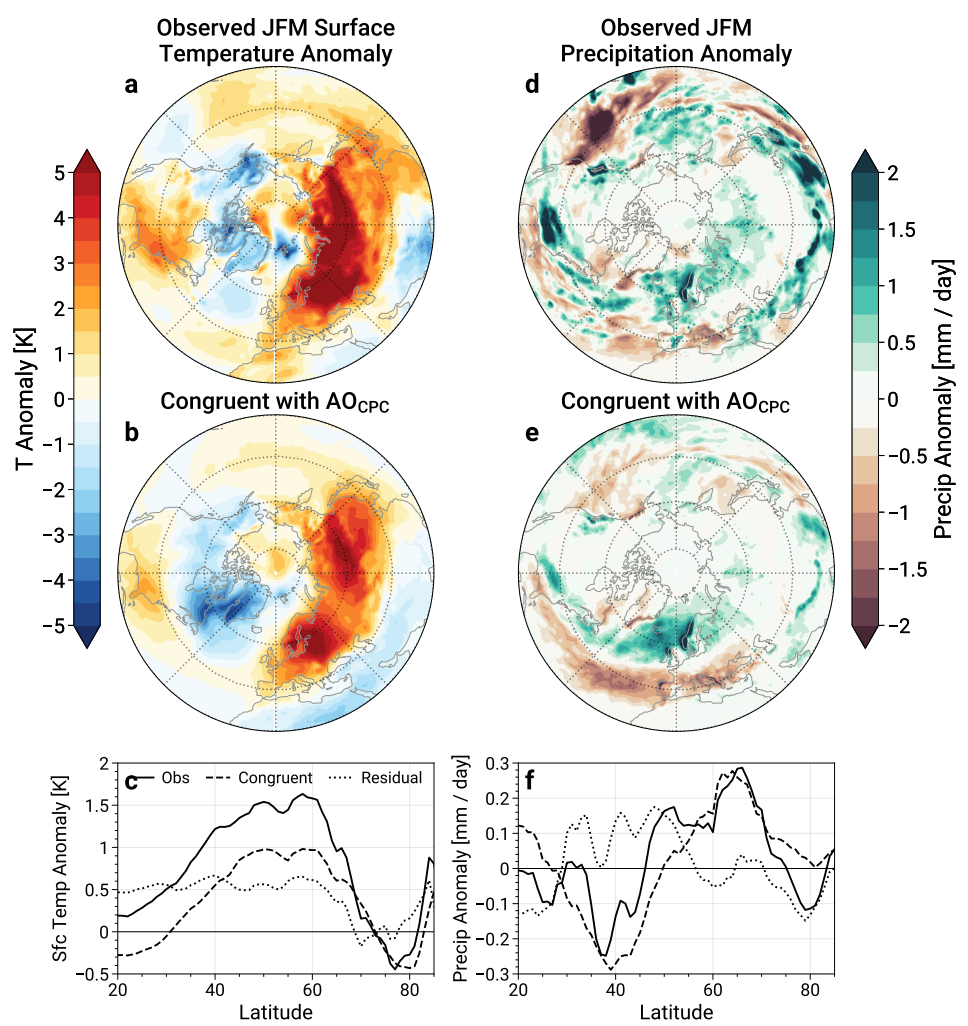

Figure 6. Maps of the observed January-March (JFM) 2020 anomalies in surface temperatures and precipitation (a,d), and the anomalies congruent with the $\mathrm{JFM} \mathrm{AO}_{C P C}(\mathrm{~b}, \mathrm{e})$. The last row shows the zonal means of the observed anomalies, the AO reconstruction, and the residuals $(\mathrm{c}, \mathrm{f})$.

tern result in amplified/dampened wave driving of the polar vortex (see, e.g., Garfinkel et al., 2010; Kolstad \& Charlton-Perez, 2011; Smith \& Kushner, 2012). Figure 7a-e shows maps of the monthly $300 \mathrm{hPa}$ geopotential height anomalies during the 2019/2020 season superposed with the climatological stationary wave patterns. November 2019 (Fig 7a) featured enhanced ridging over the Gulf of Alaska and the Ural mountains region. The patterns of $300 \mathrm{hPa}$ geopotential height anomalies were generally constructive with the climatological stationary waves, which indicates enhanced wave driving occurred during this time. This is consistent with the positive anomalies in $40-80^{\circ} \mathrm{N} \mathrm{F}_{z}$ (Fig $7 \mathrm{f}$ ) in the troposphere and stratosphere from mid to late November, which were associated with a short duration vortex weakening event (see, e.g., Figures 1 and 3). The December geopotential height anomalies (Fig 7b) show less coherent interference patterns, which is consistent with the alternating periods of positive and negative $\mathrm{F}_{z}$ anomalies within the troposphere. In contrast, January 2020 featured geopotential height anomaly patterns in a configuration that destructively interfered with the climatological stationary waves, particularly over North America and the Pacific ocean. January also had persistent anomalously low values of $\mathrm{F}_{z}$ in both the troposphere and stratosphere, indicating a prolonged period of low upward wave activity in the stratosphere. Geopotential height anomalies during February and March 2020 (Fig 7d,e) primarily show the canonical development of the positive NAM/AO state, with negative anomalies in the polar cap, and positive anomalies in the midlatitudes, similar to the SLP pattern shown in Figure 5. We showed above that upward wave activity averaged over DJF was anomalously low in the troposphere and stratosphere (Figures 3 and 4). However, there are several periods through- 
out the extended $2019 / 2020$ season when $\mathrm{F}_{z}$ was anomalously high, particularly in the stratosphere, such as in mid-to-late November, mid-December to early January, late January/early February, and mid-March (Fig 7f).

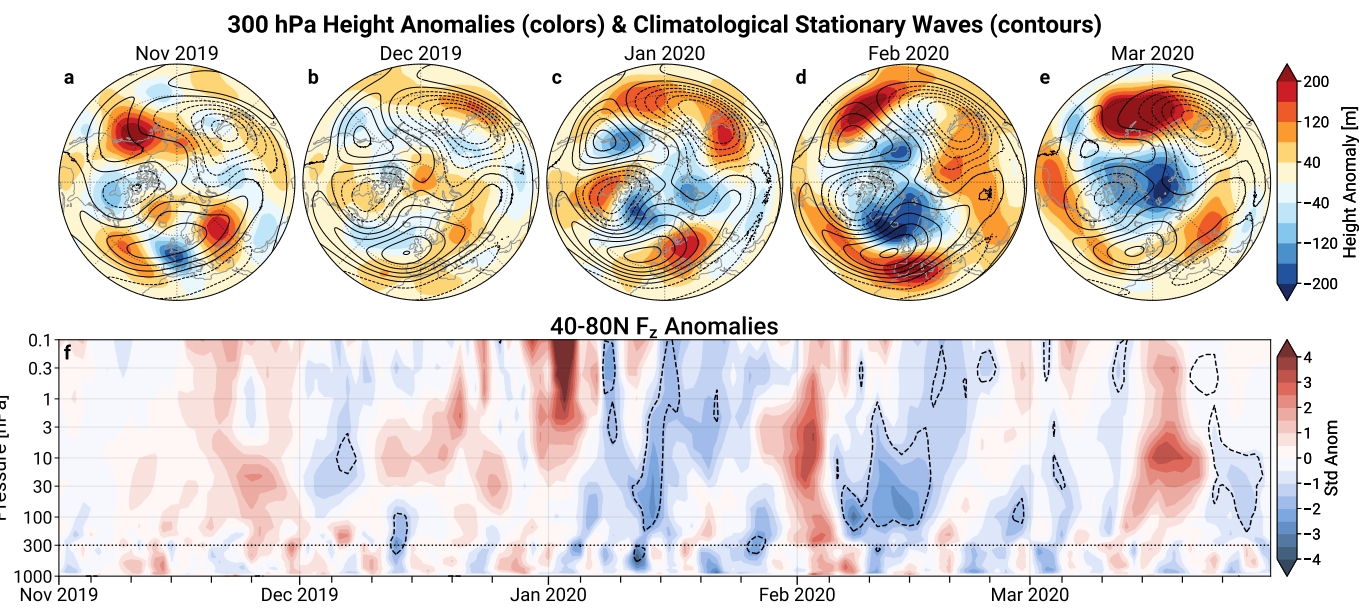

Figure 7. Maps of monthly $300 \mathrm{hPa}$ geopotential height anomalies (color fill) and climatological eddy heights representing the climatological stationary waves for November 2019 - March 2020 ( $\mathrm{a}-\mathrm{e}$ ). The bottom row (f) shows the daily time series of standardized anomalies in the 40 $-80^{\circ} \mathrm{N}$ average upward component of the Eliassen-Palm flux $\left(\mathrm{F}_{z}\right.$; values are standardized using only October - March anomalies). Contours for eddy heights in the maps of a - e are plotted every $40 \mathrm{~m}$ for values between -200 and $200 \mathrm{~m}$. Dashed contours in panel $\mathrm{f}$ show the times when the $40-80^{\circ} \mathrm{N}$ average meridional heat flux was negative.

Somewhat paradoxically, the transient positive $\mathrm{F}_{z}$ anomalies indicative of enhanced wave activity in the stratosphere likely played a role in promoting the robust polar vortex during the 2019/2020 season. The dashed contours in Figure $7 f$ indicate when the $40-80^{\circ} \mathrm{N}$ averaged meridional eddy heat flux $\left(\overline{v^{\prime} T^{\prime}}\right)$ was negative. The vertical component of the EP-Flux, $\mathrm{F}_{z}$, involves a term proportional to the eddy heat flux and tends to be dominated by it (Andrews et al., 1987); therefore, the prolonged periods of negative stratospheric heat fluxes in January, February, and March were generally periods of time when wave propagation was downward as opposed to upward, indicative of wave reflection. The low seasonal $\mathrm{F}_{z}$ values shown in Figures $3 \mathrm{c}$ and 4, particularly at $100 \mathrm{hPa}$ are thus partly a manifestation of averaging over enhanced downward wave activity, not just less upward wave activity.

It is well known that wave-mean flow interactions with planetary scale waves drive wintertime polar stratospheric temperatures away from radiative equilibrium; the deposition of easterly momentum by upward propagating planetary waves establishes a meridional residual circulation, which drives a polar downwelling that adiabatically warms the polar stratosphere (e.g., Andrews et al., 1987). However, total negative heat flux events which involve downward wave propagation, can have an episodic effect on the residual circulation by causing it to reverse with upward motion in the polar cap, leading to transient adiabatic cooling of the polar stratosphere and strengthening of the polar vortex (Shaw \& Perlwitz, 2013, 2014). These kinds of downward wave coupling events preferentially occur when the configuration of stratospheric winds support wave reflection, particularly for zonal wavenumber-1 waves (Perlwitz \& Harnik, 2003; Harnik, 2009; Shaw et al., 2010; Shaw \& Perlwitz, 2013). 
The zonal wind pattern in mid- and late winter 2020 evolved into such a reflective configuration. Figures 8a-e show monthly mean zonal mean zonal winds and EP-Flux vectors. Zonal winds in November and December (Fig 8a,b) primarily featured a single broad stratospheric jet with positive zonal wind shear over much of the extratropics. The average EP-Flux vectors during this time indicate wave propagation within the regions of strong westerlies through the stratosphere, with equatorward propagation inhibited by the regions of easterlies in the tropical stratosphere. Beginning in January and persisting through March (Fig 8c,d,e), a "split" jet structure emerged involving a high latitude jet maximum (around $60-70^{\circ} \mathrm{N}$ ) in the lower to upper stratosphere, and a low latitude subtropical jet maximum (around $30-40^{\circ} \mathrm{N}$ ) in the USLM. This configuration of the polar vortex features strong curvature of the zonal winds, a zonal wind minima in the lower and middle stratosphere that extends from low to mid-latitudes, and negative zonal wind shear at latitudes around $60^{\circ} \mathrm{N}$ in the middle to upper stratosphere (see also Fig 1b). This configuration has been shown to be highly reflective for stationary wavenumber1 waves because the zonal wind minima in the low-mid latitude lower and middle stratosphere act to meridionally confine waves, and the strong negative zonal wind shear acts as a vertical "cap" beyond which wave propagation is impaired (Perlwitz \& Harnik, 2003; Harnik, 2009; Shaw et al., 2010). Since reflection events are relatively transient, the monthlyaverage EP-Flux vectors generally do not show signs of wave reflection (downward pointing arrows) over the months of January - March; however, they do demonstrate the vertical cap in the high-latitude regions of negative zonal wind shear where wave propagation is inhibited (particularly in Fig 8c,d), despite the winds being westerly.

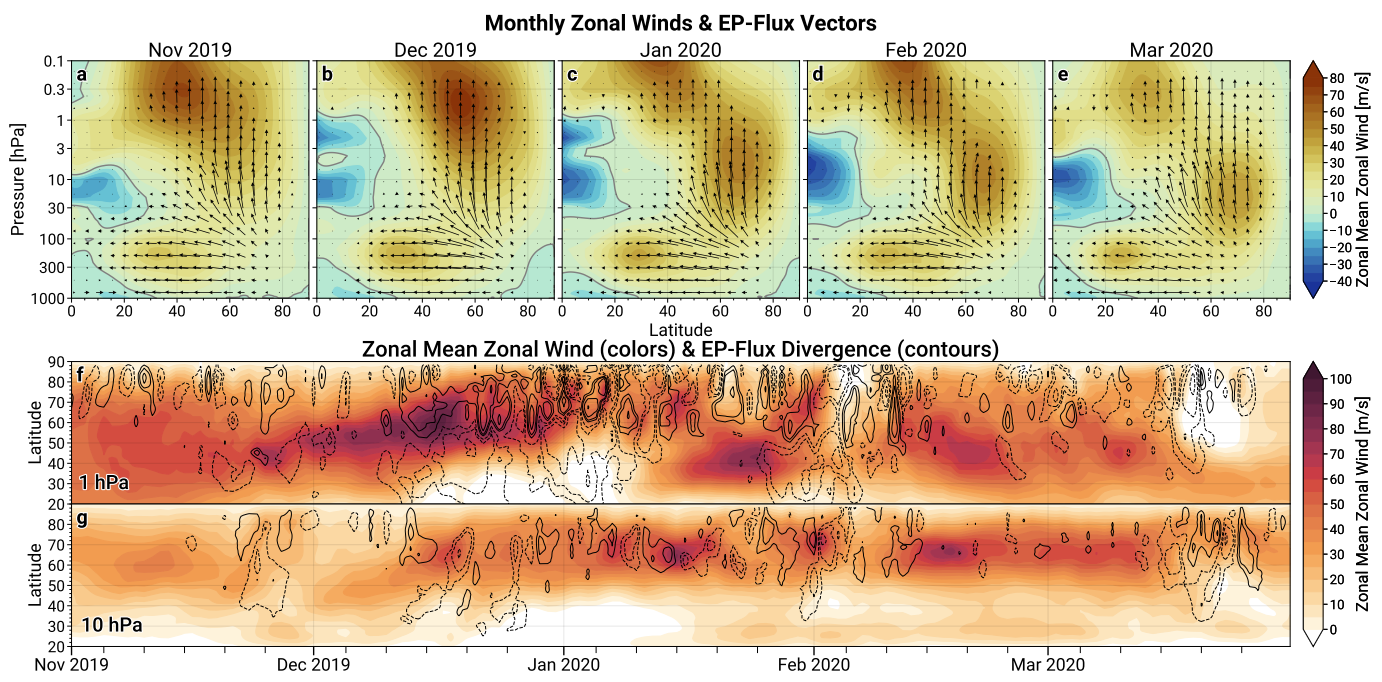

Figure 8. Latitude-pressure cross-sections of monthly zonal mean zonal winds and EP-flux vectors for November 2019 - March 2020 (a - e). The two bottom rows show latitude time series of zonal mean zonal winds at 1 (f) and 10 (g) hPa with contours of the acceleration by the EP-flux divergence overlaid. Only relatively extreme values of EP-flux divergence are plotted, for contours of $\pm[8,16,32,64] \mathrm{m} / \mathrm{s} /$ day (contours for $0 \mathrm{~m} / \mathrm{s} /$ day are excluded).

This split-jet polar vortex structure initially developed following a transient disturbance in early January that primarily affected the vortex within the USLM (see Fig 7f). Figure 8f,g show latitude/time series of zonal winds and acceleration by EP-Flux divergence from November through March at 10 and $1 \mathrm{hPa}$. While the jet maximum at $1 \mathrm{hPa}$ began the season at relatively low latitudes around $40^{\circ} \mathrm{N}$, it shifted poleward under wave driving before being nearly eroded away in early January. Due to the decreases in den- 


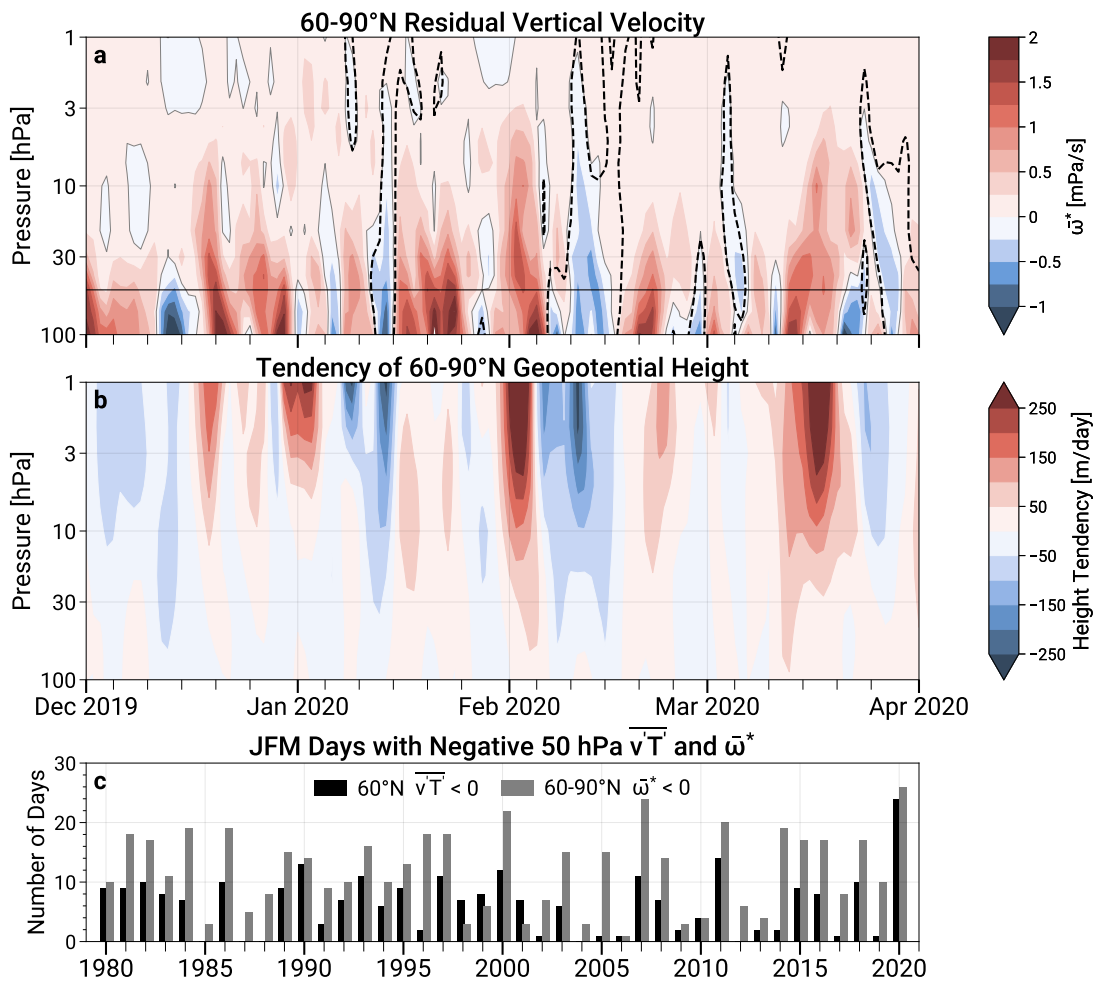

sity with altitude, waves that reach the upper stratosphere tend to grow to large amplitudes and break there, resulting in warming of the polar upper stratosphere, and a poleward movement of the vortex edge like that shown here (Dunkerton \& Delisi, 1986; Dunkerton, 2000; Scott et al., 2004). However, radiative time scales are short at these altitudes (e.g., Newman \& Rosenfield, 1997), meaning that fast cooling under radiative relaxation can allow the rapid re-establishment of the upper stratospheric jet maximum at lower latitudes (e.g., Dunkerton \& Delisi, 1985; Dunkerton, 2000). This process is consistent with the zonal wind evolution at $1 \mathrm{hPa}$ (and higher altitudes; not shown) in January, and it repeated in February. The polar vortex jet at $10 \mathrm{hPa}$ remained comparatively undisturbed during these times (Fig 8g) due to the transient nature of the upward wave pulses, meaning negative wind shear developed between the middle and upper stratosphere around $60-70^{\circ} \mathrm{N}$ (associated with the upper-level negative wind anomalies in Fig 1b). The negative heat flux events only occurred following the establishment of the negative shear and during the recovery of the mid-latitude USLM jet (associated with the "split" in the zonal mean). 
son. Figure 9 shows the $60-90^{\circ} \mathrm{N}$ average residual vertical pressure velocity $\left(\bar{\omega}^{*}\right)$ and time tendencies of polar cap geopotential heights. The periods with negative heat fluxes at $60^{\circ} \mathrm{N}$ are highlighted in Figure 9a by dashed contours. These events clearly correspond to reversals in the residual velocity that span almost the full polar stratospheric column. These events also coincide with negative $60-90^{\circ} \mathrm{N}$ polar cap height tendencies (Fig 9b). These polar cap height tendencies closely relate to changes in the thickness of the stratospheric column, and the stratospheric NAM (which we have previously defined using 65$90^{\circ} \mathrm{N}$ polar cap heights), and thus the negative tendencies generally indicate the vortex cooled and strengthened during these events, consistent with prior studies (Shaw \& Perlwitz, 2013, 2014; Dunn-Sigouin \& Shaw, 2015). We further find that the 2020 JFM season featured the largest number of days at $50 \mathrm{hPa}$ with negative heat fluxes at $60^{\circ} \mathrm{N}$ and with a reversed polar cap residual vertical velocity in the MERRA-2 record (Fig 9c). Other years with large numbers of days with negative heat fluxes include 1989/1990, 1999/2000, and 2010/2011, which are all years that featured strong seasonal-mean polar vortices (see, e.g., Figure 3). However, 2019/2020 stands out even among these, having roughly double their number of days with negative heat fluxes. We also note that generally the winters having $10+$ days with negative heat fluxes also featured one or more months with a split jet configuration in the zonal mean winds (not shown), similar to 2019/2020.

\subsection{Polar Processing and Ozone Loss}

The extremes in two-way wave coupling contributed to developing and maintaining a record strong polar vortex, which contributed to record ozone loss. Here we will show how characteristics of the polar vortex and conditions within it were conducive for the chemical destruction of ozone. We examine diagnostics of polar processing, and compare with other years with strong and cold polar vortices and/or large ozone loss, including 1996/1997 (Coy et al., 1997; Manney et al., 1997; Newman et al., 1997), 2010/2011 (Manney et al., 2011), and 2015/2016 (Manney \& Lawrence, 2016; Matthias et al., 2016). While the 2015/2016 winter did not culminate in a significant early-spring stratospheric ozone deficit, it did feature a very strong and unusually cold polar vortex that was cut short because of an early final warming. In this way, 2015/2016 serves as a foil to the other cases as an example of extreme polar processing conditions that did not lead to an extreme in stratospheric ozone.

The 2019/2020 polar vortex was exceptionally strong and long lived in the lower stratosphere, providing a robust containment vessel for chemical processing to occur in early spring as sunlight returned. Figure 10 shows time series of vortex area and maximum potential vorticity (PV) gradients on the $490 \mathrm{~K}$ isentropic surface (around 50 - 60 $\mathrm{hPa}$ ). While the $2019 / 2020$ vortex at $490 \mathrm{~K}$ was larger than normal in November, it was only about average size from December through January. However, the vortex remained at a roughly constant size between 20-25 million $\mathrm{km}^{2}$ until the beginning of April, at which point its size was among the largest on record. In the lower stratosphere, strong PV gradients are known to inhibit mixing into and out of the vortex, and thus the magnitude of PV gradients describes how well the vortex edge acts as a barrier to transport (e.g., Hoskins et al., 1985; Juckes \& McIntyre, 1987; Scott et al., 2004). Here we show PV gradients as a function of equivalent latitude, which describe how closely contours of PV are spaced in an equivalent area coordinate system (see, e.g., Butchart \& Remsberg, 1986). The daily maximum PV gradients (which generally occur at the polar vortex edge) over the $2019 / 2020$ season started out near normal but became anomalously strong beginning in January before reaching all-time record highs in February through April (Fig 10c). The size of the lower stratospheric vortex during 2019/2020 remained above 10 million $\mathrm{km}^{2}$ longer than any other previous year (Fig 10b), even 1996/1997, which had the largest vortex region from late March through the beginning of May. Similarly, the extended November-April 2020 mean maximum PV gradients were the largest in the MERRA2 record (Fig 10d). 

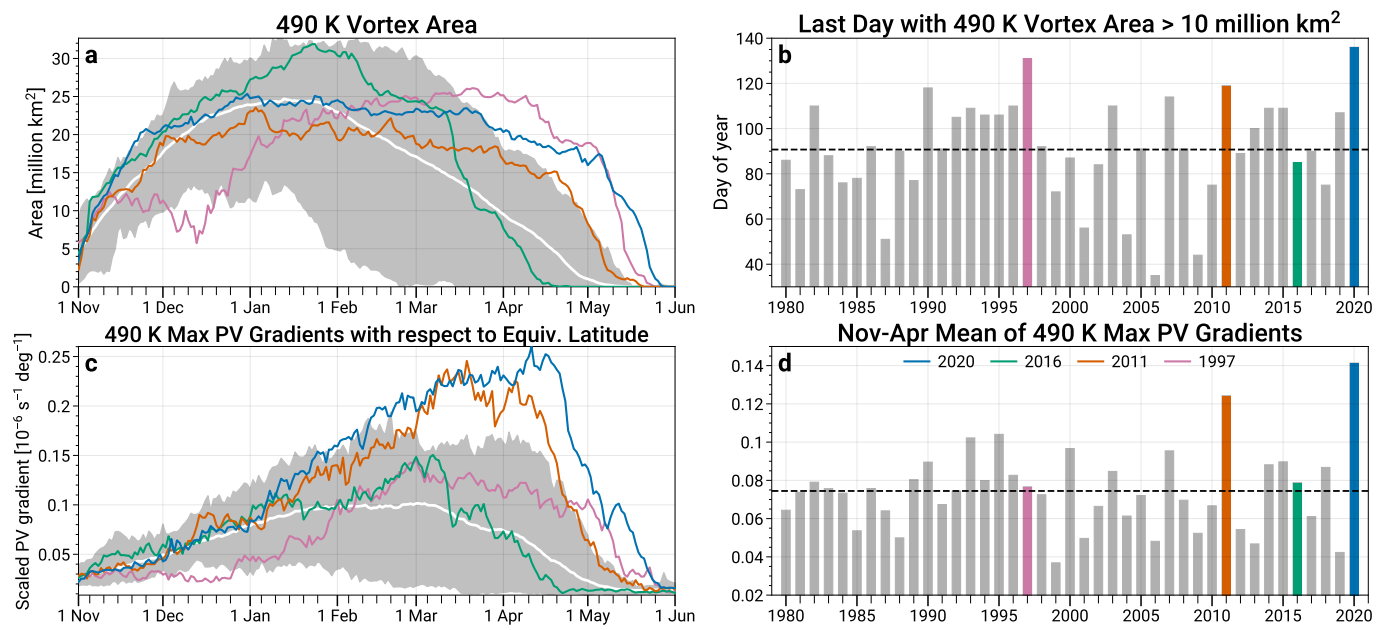

Figure 10. The left column shows daily time series of $490 \mathrm{~K}$ vortex area (a), and maximum PV gradients with respect to equivalent latitude (c). The right column shows derived statistics including the last day with $490 \mathrm{~K}$ vortex area above 10 million $\mathrm{km}^{2}$ (b), and the November-March mean of the maximum PV gradients (d). The 2019/2020 season is highlighted in blue, with other relevant winters shown in green $(2015 / 2016)$, orange $(2010 / 2011)$ and pink (1996/1997). The grey envelopes and white lines in panels a and c represent (respectively) the climatological ranges and means after excluding the four highlighted years. The dashed horizontal lines in panels $\mathrm{b}$ and $\mathrm{d}$ represent the climatological average across the available years.

The 2019/2020 polar vortex was also the coldest in the MERRA-2 record for the formation of PSCs. In Figure 11, daily minimum temperatures at $50 \mathrm{hPa}$ (Figures 11a) reached some all-time record lows in late November and early December, and temperatures remained lower than the formation threshold for nitric acid trihydrate (NAT) PSCs until approximately March 25th. While this was not the latest date on record, 2019/2020 still had the largest total number of days with temperatures below $\mathrm{T}_{N A T}$ (Fig 11b) because of the early onset of the cold period. The vortex volume fraction of lower stratospheric air with temperatures below $\mathrm{T}_{N A T}\left(V_{N A T} / V_{\text {vort }}\right)$ paints a consistent picture (Fig 11c); the 2019/2020 season attained all-time record maxima during some periods in mid-November and early December. Thereafter, the pool of cold air within the vortex remained relatively stable between fractions of 0.4 - 0.5 until early March (except for a brief dip in early February). Figure 11d suggests that roughly a third of the vortex volume in the lower stratosphere contained temperatures conducive to the formation of PSCs in the seasonal mean, the largest in any year in the MERRA-2 record.

Based on the results shown here, the 2019/2020 season had the greatest ozone loss potential ever observed. The polar processing conditions over the 2019/2020 season most closely resembled that seen during 2010/2011, which also had a relatively constant-sized vortex until late in the season, anomalously large PV gradients, and an extensive period of low temperatures. The 2015/2016 season also had an early onset of low temperatures and still holds some records for cold, but the vortex weakened much earlier in a dynamic final warming. The 1996/1997 season was effectively delayed by a month because an early winter warming kept the vortex small, weak, and warm, meaning less time was available for polar processing to occur.

Column ozone amounts in late winter and early spring suggest that exceptional chemical ozone loss did occur: Figure 12 shows the February-April (FMA) 2020 mean column 

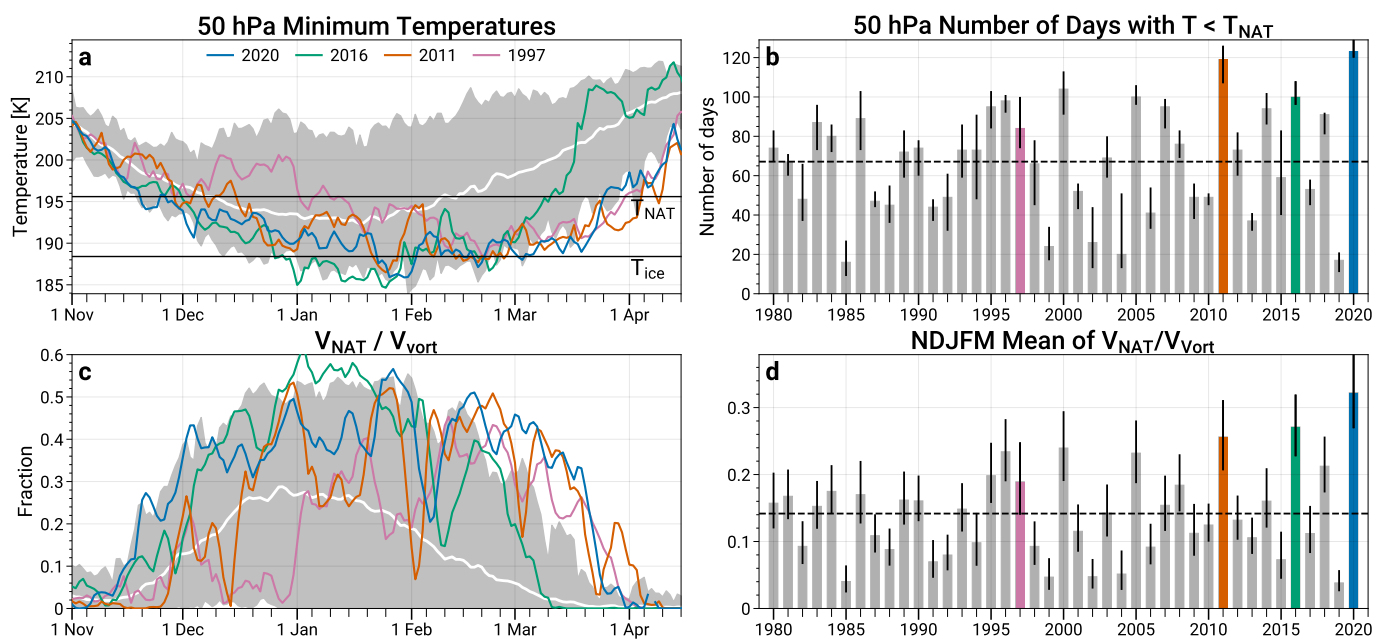

Figure 11. As in Figure 10, but the left column shows daily time series of $50 \mathrm{hPa}$ minimum temperatures poleward of $40^{\circ} \mathrm{N}$ (a), and the volume of air in the lower stratosphere with temperatures below the nitric acid trihydrate (NAT) polar stratospheric cloud (PSC) threshold ( $\mathrm{T}_{N A T}$ ) normalized by the vortex volume $\left(\mathrm{V}_{N A T} / \mathrm{V}_{\text {vort }} ; \mathrm{c}\right)$. The right column shows yearly integrated statistics, including the total number of days with temperatures below $\mathrm{T}_{N A T}$ at $50 \mathrm{hPa}$, and the November-March mean $\mathrm{V}_{N A T} / \mathrm{V}_{\text {vort }}(\mathrm{d})$. Panel a has labeled horizontal black lines that represent the approximate formation thresholds for NAT and ice PSCs. The whiskers in panels $\mathrm{b}$ and $\mathrm{d}$ represent the ranges from accounting for $\pm 1 \mathrm{~K}$ uncertainties in the specific $\mathrm{T}_{N A T}$ threshold.

ozone anomalies alongside yearly time series of the FMA average of polar cap $\left(63-90^{\circ} \mathrm{N}\right)$ column ozone back to 1979 (the period over which regular total column ozone measurements were made by satellite instruments). Figure 12a shows that column ozone was anomalously low by more than 100 Dobson units (DU) over the pole for these three months. This ozone deficit is further reflected by the polar cap average time series shown in Figure $12 \mathrm{~b}$, which shows that the 2020 FMA mean was the lowest on record since 1979, with a seasonal average less than $340 \mathrm{DU}$. The interpretation of low total column ozone amounts as they relate to chemical ozone depletion requires great caution, as dynamical influences related to tropospheric weather systems, lower stratospheric cold pools, and the location of the tropopause can cumulatively help to induce low column ozone amounts on daily to seasonal timescales (e.g., see discussions in Petzoldt, 1999; Manney et al., 2011). Reduced wave driving of the polar vortex and/or more frequent downward wave coupling events additionally lead to a weakened residual circulation that reduces the vertical resupply of ozone, which can project onto anomalously low total column ozone amounts (Tegtmeier et al., 2008; Shaw \& Perlwitz, 2014; Lubis et al., 2017). However, the combination of the persistent polar processing conditions conducive for chemical loss, and the persistently low column ozone values point to chemical depletion in 2019/2020 being a large factor. Further, Manney et al. (2020) show evidence of chemical loss in verticallyresolved ozone profiles matching or exceeding that in 2011.

\section{Discussion}

We have provided a description of the unusual 2019/2020 polar vortex, and how it related to the observed climate extremes in the Arctic Oscillation and stratospheric ozone. Our results particularly highlight the important confluence of tropospheric and stratospheric conditions that overall made the exceptional polar vortex, AO, and ozone 

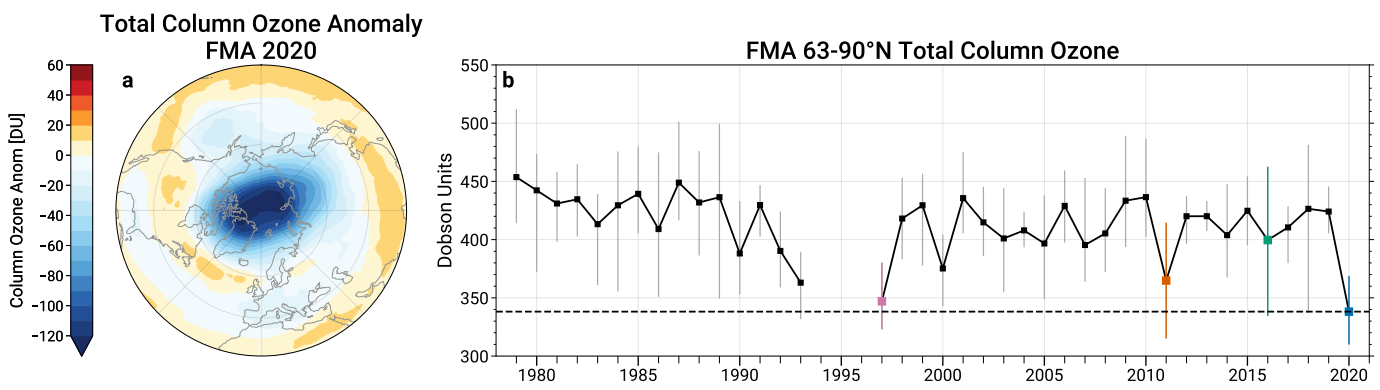

Figure 12. Map of Northern Hemisphere total column ozone anomalies averaged over February-April (FMA) 2020 (a) and yearly time series of the FMA mean $63-90^{\circ} \mathrm{N}$ polar cap ozone. The whiskers in panel $\mathrm{b}$ represent the range of the polar cap ozone values during the respective FMA seasons; the black dashed horizontal line is plotted at the mean value for 2020 . The winters of 2019/2020, 2015/2016, 2010/2011, 1996/1997 are highlighted in the same colors as in Figures 10 and 11. The missing data between 1994-1996 is during a period without satellite column ozone observations.

depletion events possible. Together these events represent impacts of the most extreme and coherently coupled strong vortex event on the spectrum of observed Northern Hemisphere winters. There are a handful of previous winter seasons such as 1996/1997, 1999/2000, and 2010/2011 that were similar in nature to $2019 / 2020$ in that they particularly involved anomalously strong, cold, and long-lived polar vortices (Figures 3 and 11), a large number of negative heat flux days (Figure 9), and polar processing conditions more conducive for chemical ozone loss (Figure 12). However, these winters generally lacked the coherent coupling with the tropospheric circulation (Figures 3 and 5). In contrast, winters such as 1989/90 and 1992/1993 featured strong polar vortices, large numbers of negative heat flux days, and persistently positive tropospheric AO events, but lacked the unusually and persistently cold polar processing conditions necessary for exceptional chemical ozone loss (Figure 11). The fact that all these factors and events coincided in the same season of 2019/2020 makes it truly extraordinary.

Our paper provided a general overview of the extremes that occured during the 2019/2020 winter and how they developed. Further studies are necessary to fill in the details of mechanisms, observations, predictability, and of the full range and magnitude of impacts. Below we pose some research questions motivated by the present work:

\section{What were the drivers (if any) of the strong vortex and/or AO events over internal} variability?

Interannual variability of the Arctic polar vortex is influenced by a variety of background climate forcings and boundary conditions that act on sub-seasonal to seasonal timescales. These "drivers" impact the generation of waves in the troposphere, or influence how they propagate through the atmosphere. Detailed modeling and attribution studies will be necessary to determine whether such processes played a role in the development of the strong polar vortex and/or the AO event over simple internal variability.

For example, sea surface temperatures (SSTs) in various regions have been linked to seasonal variability in the Arctic polar vortex. Some studies tied the previous strong and cold springtime polar vortices of 1997 and 2011 to positive SST anomalies in the north central Pacific (Hurwitz et al., 2011, 2012); more generally, SSTs in this region have been shown to modulate tropospheric planetary wave activity and the strength of the vortex 
(e.g., Hu et al., 2018; Xie et al., 2020). Positive SST anomalies in the Indian Ocean have also been shown to encourage a strengthened Arctic polar vortex and positive NAM in the troposphere (Hoerling \& Kumar, 2002; Hoerling et al., 2004; Li et al., 2010; Fletcher \& Kushner, 2011), particularly in isolation from impacts by the El Niño-Southern Oscillation (ENSO) (Fletcher \& Cassou, 2015). It is worth noting that the boreal autumn of 2019 featured a record strong Indian Ocean dipole (IOD) event (see, e.g., Johnson, 2020) and warm north Pacific SSTs from a marine heatwave (see, e.g., L'Heureux, 2019), amidst largely neutral ENSO conditions. A recent study by Hardiman et al. (2020) attributes predictability of the North Atlantic Oscillation (NAO) during winter 2019/2020 to this unusual IOD event, and particularly highlights the role of a stratospheric pathway related to a strengthened polar vortex. Other background forcings and boundary conditions that have been shown to impact the polar vortex include the tropical tropospheric Madden-Julian oscillation (e.g., Garfinkel, Feldstein, et al., 2012; Garfinkel et al., 2014; Liu et al., 2014; R. W. Lee et al., 2019), and the tropical stratospheric quasi-biennial oscillation (QBO; e.g., Baldwin et al., 2001; Garfinkel, Shaw, et al., 2012; White et al., 2016; Lubis et al., 2016; Lu et al., 2020). The QBO during the 2019/2020 winter was in the midst of a "disruption", the second on record (Anstey et al., 2020), and it is presently unknown how such a disruption may have impacted the Arctic polar vortex during the season.

2. How well were the strong polar vortex and AO events predicted by sub-seasonal to seasonal forecast models, and did the stratosphere contribute to tropospheric forecast skill?

It is possible that some fraction of skill in sub-seasonal to seasonal $(\mathrm{S} 2 \mathrm{~S})$ forecasts during the 2019/2020 winter and spring could be related to skill in predicting the strong polar vortex event, or being initialized with it. Studies have consistently shown a relationship between wintertime polar stratospheric initial conditions and improved S2S forecast skill (e.g., Sigmond et al., 2013; Tripathi, Baldwin, et al., 2015; Tripathi, CharltonPerez, et al., 2015; Scaife et al., 2016; Nie et al., 2019). Recent work suggests there is also a relationship between model skill in predicting the stratosphere and skill for the troposphere (e.g., Domeisen et al., 2020a, 2020b). As mentioned above, a recent study by Hardiman et al. (2020) finds that the IOD conditions in late autumn/early winter influenced the strength of the polar vortex, which then impacted the NAO. Another recent study submitted for this special issue by S. H. Lee et al. (2020) found that ensemble members in a multi-model composite of seasonal forecasts that better predicted the strength of the $2019 / 2020$ polar vortex also better predicted the anomalous tropospheric state.

A more complete accounting of the impacts related to stratosphere-troposphere coupling is also warranted: the reflective state of the stratosphere and multiple downward wave coupling events may have had a direct influence on tropospheric weather and circulation during the 2019/2020 winter and early spring. Downward wave reflection events have themselves been shown to help initiate positive phases of the North Atlantic Oscillation (Shaw \& Perlwitz, 2013; Dunn-Sigouin \& Shaw, 2015), and to occasionally directly induce weather events such as North Pacific blocking and cold spells in North America and Eurasia (Kodera et al., 2008; Kodera \& Mukougawa, 2017; Matthias \& Kretschmer, 2020).

\section{What were the relative roles of dynamical transport versus chemical loss processes in} determining the low early spring column ozone?

The anomalous polar cap ozone during the late winter and early spring of 2020 was clearly record breaking. The low ozone is generally consistent with the persistently strong polar vortex, which would have led to depressed ozone amounts due to a weakened residual circulation, and enhanced chemical loss due to the persistently cold polar vortex (Tegtmeier et al., 2008; Shaw \& Perlwitz, 2014; Lubis et al., 2017). In 2010/2011 (the winter previously having the most extreme ozone loss) the individual contributions from transport 
and chemical loss were both found to be record breaking based on a mixture of observations and models (e.g., Balis et al., 2011; Manney et al., 2011; Sinnhuber et al., 2011; Adams et al., 2012; Strahan et al., 2013; Griffin et al., 2019). It will similarly be necessary for studies to utilize a variety of observations and models to determine the relative roles of dynamical versus chemical impacts on low column ozone in spring 2020, in addition to providing quantitative vertically-resolved chemical loss estimates. For example, Manney et al. (2020, published in this special collection) use observations of relevant chemical species from the Aura Microwave Limb Sounder to illustrate the chemical and transport processes leading to exceptional chemical ozone loss and record low ozone by spring 2020. Other studies presently submitted for this special collection and elsewhere further explore the detailed evolution of ozone during the season using a variety of measurements and models (Dameris et al., 2020; Grooß \& Müller, 2020; Inness et al., 2020; Wohltmann et al., 2020), and more are in preparation.

\section{Were there downstream impacts related to the strong vortex, ozone deficit, and per-} sistent positive tropospheric AO events?

The strong polar vortex, low ozone, and positive AO events that occurred in the late winter/early spring of 2020 were each record breaking on seasonal timescales, and as a result, there is a possibility they had farther-reaching consequences. For example, it is possible that the depleted ozone into spring 2020 may have helped to maintain the positive AO through April. One modeling study has shown that negative Arctic ozone anomalies can cause a feedback on the strength of the vortex that increases the probability of a positive tropospheric AO (Karpechko et al., 2014), in a similar manner to the observed tropospheric impacts of the Antarctic ozone hole (Thompson \& Solomon, 2002; Shindell \& Schmidt, 2004; Thompson et al., 2011). This kind of relationship between stratospheric ozone and the tropospheric circulation underpins why recent studies have suggested that springtime Arctic stratospheric ozone anomalies are linked with surface temperatures and precipitation in specific regions for weeks to months ahead (e.g., Calvo et al., 2015; Ivy et al., 2017; Xie et al., 2018; Stone et al., 2019; Wang et al., 2020).

Additional climatologically relevant impacts are also possible: One recent study illustrated that springtime stratospheric ozone intrusions are strongly impacted by the abundance of ozone in the lowermost stratosphere in early spring (Albers et al., 2018), meaning there could be a signature of the 2020 low ozone event in subsequent ozone intrusions of spring 2020. Another recent study has shown a relationship between a positive $\mathrm{AO}$ in the winter and early spring and increased fire activity and burn area in southeastern Siberia, a region where carbon release by fires can accelerate Arctic warming (Kim et al., 2020). Yet another recent study has found a link between the timing of the springtime Arctic polar vortex breakdown and the distribution of sea ice thickness anomalies all the way until the following autumn (Kelleher et al., 2020). Further study will be required to determine whether responses consistent with the above mentioned relationships, or other events, arise due to influences from the exceptional 2019/2020 winter and spring.

These and other questions will be the focus of further work; we expect that many will be addressed in the Journal of Geophysical Research/Geophysical Research Letters Special Collection on the exceptional 2019/2020 Arctic polar vortex in which this article appears.

\section{Conclusions}

The 2019/2020 NH stratospheric polar vortex was remarkably strong. The westerly stratospheric circulation represented by the polar vortex was the strongest on record for December-March winter seasons back to 1979/1980; if considering earlier years back to $1958 / 1959$ for which data are more uncertain, 2019/2020 ranks among the top three, although it depends on the specific level under consideration (e.g., 2019/2020 remains 
the strongest at $100 \mathrm{hPa}$ ). The robust polar vortex appears to have developed due to a combination of weak tropospheric wave driving and a series of downward wave coupling events that occurred following the development of a reflective configuration of the polar vortex. Numerous aspects of the 2019/2020 winter and early spring were record breaking, and involved extremes in two-way troposphere-stratosphere coupling.

The positive AO and positive stratospheric NAM developed as a coherent event spanning the troposphere and stratosphere. As a result, the direction of causality between the strongly positive NAM in the stratosphere and strongly positive AO in the troposphere is somewhat unclear. However, the persistence of the exceptionally strong vortex throughout the stratosphere suggests a stratospheric influence on the AO is more likely. Furthermore, downward wave coupling events are known to initiate tropospheric circulation anomalies consistent with a positive AO (Shaw \& Perlwitz, 2013; Dunn-Sigouin \& Shaw, 2015), meaning that the stratospheric wave reflection events that occurred during the 2019/2020 winter likely helped to maintain the positive AO. The January-March 2020 mean AO was the largest on record and persistently positive. Large fractions of the observed surface temperature and precipitation anomalies in JFM were consistent with this large amplitude $\mathrm{AO}$ event, including a large portion of the record warmth that occurred over Eurasia.

The strong and long-lived polar vortex also provided ideal conditions for chemical ozone destruction to take place. In the lower stratosphere, the polar vortex was a robust transport barrier and very long lived, which isolated Arctic air during the key transition period out of polar night. Furthermore, temperatures low enough to form polar stratospheric clouds within the vortex developed early in the season, and on average enclosed about a third of the vortex volume. In total, the number of days with such low temperatures exceeded 4 months. These conditions are unprecedented back to 1979/1980, making 2019/2020 the season with the greatest ozone loss potential on record. Polar cap column ozone amounts subsequently reached low levels never before observed in the Arctic at this time of year.

\section{Acknowledgments}

We thank John Albers for providing comments on an early version of the manuscript. We are also grateful to three anonymous reviewers whose comments helped to improve this manuscript. Lastly, we thank the Microwave Limb Sounder team for computational support related to calculating the polar processing diagnostics. ZDL and JP acknowledge support from Federally Appropriated Funds. SHL acknowledges funding by the Natural Environment Research Council (NERC) via SCENARIO (NE/L002566/1)

The datasets used herein are publicly available. NASA MERRA-2 data are available from NASA's GES DISC at https://disc.gsfc.nasa.gov/datasets?keywords= MERRA-2. JRA-55 data are available from the NCAR Research Data Archive at https:// rda.ucar.edu/datasets/ds628.0/. The CPC AO index is kept up to date at https:// www.cpc.ncep.noaa.gov/products/precip/CWlink/daily_ao_index/ao.shtml. Ozone data and statistics from OMPS and other instruments are compiled and made available via NASA's OzoneWatch resource at https://ozonewatch.gsfc.nasa.gov/data/. 


\section{References}

Adams, C., Strong, K., Zhao, X., Bassford, M. R., Chipperfield, M. P., Daffer, W., ... Walker, K. A. (2012). Severe 2011 ozone depletion assessed with 11 years of ozone, NO2, and $\mathrm{OClO}$ measurements at 80N. Geophysical Research Letters, 39(5). doi: 10.1029/2011GL050478

Albers, J. R., Perlwitz, J., Butler, A. H., Birner, T., Kiladis, G. N., Lawrence, Z. D., .. Dias, J. (2018). Mechanisms Governing Interannual Variability of Stratosphere-to-Troposphere Ozone Transport. Journal of Geophysical Research: Atmospheres, 123(1), 234-260. doi: 10.1002/2017JD026890

Andrews, D. G., Leovy, C. B., \& Holton, J. R. (1987). Middle Atmosphere Dynamics. Academic Press.

Anstey, J. A., Banyard, T. P., Butchart, N., Coy, L., Newman, P. A., Osprey, S., \& Wright, C. (2020). Quasi-biennial oscillation disrupted by abnormal Southern Hemisphere stratosphere. Earth and Space Science Open Archive.

Baldwin, M. P. (2001). Annular modes in global daily surface pressure. Geophysical Research Letters, 28(21), 4115-4118. doi: 10.1029/2001GL013564

Baldwin, M. P., \& Dunkerton, T. J. (2001). Stratospheric Harbingers of Anomalous Weather Regimes. Science, 294(5542), 581-584. doi: 10.1126/science.1063315

Baldwin, M. P., Gray, L. J., Dunkerton, T. J., Hamilton, K., Haynes, P. H., Randel, W. J., ... Takahashi, M. (2001). The quasi-biennial oscillation. Reviews of Geophysics, 39(2), 179-229. doi: 10.1029/1999RG000073

Baldwin, M. P., \& Thompson, D. W. J. (2009). A critical comparison of stratosphere-troposphere coupling indices. Quarterly Journal of the Royal Meteorological Society, 135(644), 1661-1672. doi: 10.1002/qj.479

Balis, D., Isaksen, I. S. A., Zerefos, C., Zyrichidou, I., Eleftheratos, K., Tourpali, K., ... Orsolini, Y. (2011). Observed and modelled record ozone decline over the Arctic during winter/spring 2011. Geophysical Research Letters, 38(23). doi: 10.1029/2011GL049259

Black, R. X., McDaniel, B. A., \& Robinson, W. A. sphere-Troposphere Coupling during Spring Onset. 19(19), 4891-4901. doi: 10.1175/JCLI3907.1

(2006). StratoJournal of Climate,

Butchart, N., \& Remsberg, E. E. (1986). The Area of the Stratospheric Polar Vortex as a Diagnostic for Tracer Transport on an Isentropic Surface. Journal of the Atmospheric Sciences, 43(13), 1319-1339. doi: 10.1175/1520-0469(1986) 043〈1319:TAOTSP $\rangle$ 2.0.CO;2

Butler, A. H., Charlton-Perez, A., Domeisen, D. I. V., Garfinkel, C., Gerber, E. P., Hitchcock, P., ... Son, S.-W. (2019). Chapter 11 - Sub-seasonal Predictability and the Stratosphere. In A. W. Robertson \& F. Vitart (Eds.), Sub-Seasonal to Seasonal Prediction (pp. 223-241). Elsevier. doi: 10.1016/B978-0-12-811714-9.00011-5

Butler, A. H., Sjoberg, J. P., Seidel, D. J., \& Rosenlof, K. H. （2017). A sudden stratospheric warming compendium. Earth System Science Data, 9(1), 63-76. doi: 10.5194/essd-9-63-2017

Calvo, N., Polvani, L. M., \& Solomon, S. (2015). On the surface impact of Arctic stratospheric ozone extremes. Environmental Research Letters, $10(9), 094003$. doi: 10.1088/1748-9326/10/9/094003

Charlton-Perez, A. J., Ferranti, L., \& Lee, R. W. (2018). The influence of the stratospheric state on North Atlantic weather regimes. Quarterly Journal of the Royal Meteorological Society, 144(713), 1140-1151. doi: 10.1002/qj.3280

Charney, J. G., \& Drazin, P. G. (1961). Propagation of planetary-scale disturbances from the lower into the upper atmosphere. Journal of Geophysical Research (1896-1977), 66(1), 83-109. doi: 10.1029/JZ066i001p00083

Cohen, J., Salstein, D., \& Saito, K. (2002). A dynamical framework to understand and predict the major Northern Hemisphere mode. Geophysical Research Letters, 29(10), 51-1-51-4. doi: 10.1029/2001GL014117 
Coy, L., Nash, E. R., \& Newman, P. A. (1997). Meteorology of the polar vortex: Spring 1997. Geophysical Research Letters, 24(22), 2693-2696. doi: 10.1029/ 97GL52832

Dameris, M., Loyola, D. G., Nützel, M., Coldewey-Egbers, M., Lerot, C., Romahn, F., \& van Roozendael, M. (2020). First description and classification of the ozone hole over the Arctic in boreal spring 2020. Atmospheric Chemistry and Physics Discussions, 1-26. doi: 10.5194/acp-2020-746

de la Cámara, A., Albers, J. R., Birner, T., Garcia, R. R., Hitchcock, P., Kinnison, D. E., \& Smith, A. K. (2017). Sensitivity of Sudden Stratospheric Warmings to Previous Stratospheric Conditions. Journal of the Atmospheric Sciences, 74 (9), 2857-2877. doi: 10.1175/JAS-D-17-0136.1

Domeisen, D. I. V. (2019). Estimating the Frequency of Sudden Stratospheric Warming Events From Surface Observations of the North Atlantic Oscillation. Journal of Geophysical Research: Atmospheres, 124(6), 3180-3194. doi: 10.1029/2018JD030077

Domeisen, D. I. V., Butler, A. H., Charlton-Perez, A. J., Ayarzagüena, B., Baldwin, M. P., Dunn-Sigouin, E., ... Taguchi, M. (2020a). The Role of the Stratosphere in Subseasonal to Seasonal Prediction: 1. Predictability of the Stratosphere. Journal of Geophysical Research: Atmospheres, 125(2), e2019JD030920. doi: 10.1029/2019JD030920

Domeisen, D. I. V., Butler, A. H., Charlton-Perez, A. J., Ayarzagüena, B., Baldwin, M. P., Dunn-Sigouin, E., ... Taguchi, M. (2020b). The Role of the Stratosphere in Subseasonal to Seasonal Prediction: 2. Predictability Arising From Stratosphere-Troposphere Coupling. Journal of Geophysical Research: Atmospheres, 125(2), e2019JD030923. doi: 10.1029/2019JD030923

Dunkerton, T. J. (2000). Midwinter Deceleration of the Subtropical Mesospheric Jet and Interannual Variability of the High-Latitude Flow in UKMO Analyses. Journal of the Atmospheric Sciences, 57(23), 3838-3855. doi: 10.1175/1520-0469(2000)057〈3838:MDOTSM $\rangle 2.0 . C O ; 2$

Dunkerton, T. J., \& Delisi, D. P. (1985). The subtropical mesospheric jet observed by the Nimbus 7 Limb Infrared Monitor of the Stratosphere. Journal of Geophysical Research: Atmospheres, 90(D6), 10681-10692. doi: 10.1029/JD090iD06p10681

Dunkerton, T. J., \& Delisi, D. P. (1986). Evolution of potential vorticity in the winter stratosphere of January-February 1979. Journal of Geophysical Research: Atmospheres, 91 (D1), 1199-1208. doi: 10.1029/JD091iD01p01199

Dunn-Sigouin, E., \& Shaw, T. (2018). Dynamics of Extreme Stratospheric Negative Heat Flux Events in an Idealized Model. Journal of the Atmospheric Sciences, 75 (10), 3521-3540. doi: 10.1175/JAS-D-17-0263.1

Dunn-Sigouin, E., \& Shaw, T. A. (2015). Comparing and contrasting extreme stratospheric events, including their coupling to the tropospheric circulation. Journal of Geophysical Research: Atmospheres, 120(4), 1374-1390. doi: 10.1002/2014JD022116

Fletcher, C. G., \& Cassou, C. (2015). The Dynamical Influence of Separate Teleconnections from the Pacific and Indian Oceans on the Northern Annular Mode. Journal of Climate, 28(20), 7985-8002. doi: 10.1175/JCLI-D-14-00839.1

Fletcher, C. G., \& Kushner, P. J. (2011). The Role of Linear Interference in the Annular Mode Response to Tropical SST Forcing. Journal of Climate, 24(3), 778-794. doi: 10.1175/2010JCLI3735.1

Garfinkel, C. I., Benedict, J. J., \& Maloney, E. D. (2014). Impact of the MJO on the boreal winter extratropical circulation. Geophysical Research Letters, 6055-6062. doi: 10.1002/2014GL061094@10.1002/(ISSN)1944-8007.ATMOS -VARIABILITY

Garfinkel, C. I., Feldstein, S. B., Waugh, D. W., Yoo, C., \& Lee, S. (2012). Observed connection between stratospheric sudden warmings and the Madden-Julian Os- 
cillation. Geophysical Research Letters, 39(18). doi: 10.1029/2012GL053144

Garfinkel, C. I., Hartmann, D. L., \& Sassi, F. (2010). Tropospheric Precursors of Anomalous Northern Hemisphere Stratospheric Polar Vortices. Journal of Climate, 23(12), 3282-3299. doi: 10.1175/2010JCLI3010.1

Garfinkel, C. I., Shaw, T. A., Hartmann, D. L., \& Waugh, D. W. (2012). Does the Holton-Tan Mechanism Explain How the Quasi-Biennial Oscillation Modulates the Arctic Polar Vortex? Journal of the Atmospheric Sciences, 69(5), 1713-1733. doi: 10.1175/JAS-D-11-0209.1

Gelaro, R., McCarty, W., Suárez, M. J., Todling, R., Molod, A., Takacs, L., .. Zhao, B. (2017). The Modern-Era Retrospective Analysis for Research and Applications, Version 2 (MERRA-2). Journal of Climate, 30(14), 5419-5454. doi: $10.1175 /$ JCLI-D-16-0758.1

GMAO. (2020a). MERRA-2 inst3_3d_asm_Np: 3d, 3-Hourly,Instantaneous,PressureLevel,Assimilation,Assimilated Meteorological Fields V5.12.4. doi: 10.5067/ QBZ6MG944HW0,

GMAO. (2020b). MERRA-2 inst3_3d_asm_Nv: 3d,3-Hourly,Instantaneous, ModelLevel,Assimilation,Assimilated Meteorological Fields V5.12.4. doi: 10.5067/ WWQSXQ8IVFW8

Griffin, D., Walker, K. A., Wohltmann, I., Dhomse, S. S., Rex, M., Chipperfield, M. P., .. Tarasick, D. (2019). Stratospheric ozone loss in the Arctic winters between 2005 and 2013 derived with ACE-FTS measurements. Atmospheric Chemistry and Physics, 19(1), 577-601. doi: 10.5194/acp-19-577-2019

Grooß, J.-U., \& Müller, R. (2020). Simulation of the record Arctic stratospheric ozone depletion in 2020. Earth and Space Science Open Archive. doi: 10.1002/ essoar.10503569.1

Hardiman, S. C., Dunstone, N. J., Scaife, A. A., Smith, D. M., Knight, J. R., Davies, P., ... Greatbatch, R. J. (2020). Predictability of European winter 2019/20: Indian Ocean dipole impacts on the NAO. Atmospheric Science Letters, $n / a(\mathrm{n} / \mathrm{a})$, e1005. doi: 10.1002/asl.1005

Harnik, N. (2009). Observed stratospheric downward reflection and its relation to upward pulses of wave activity. Journal of Geophysical Research: Atmospheres, 114(D8). doi: 10.1029/2008JD010493

Hitchcock, P. (2019). On the value of reanalyses prior to 1979 for dynamical studies of stratosphere-troposphere coupling. Atmospheric Chemistry and Physics, 19(5), 2749-2764. doi: 10.5194/acp-19-2749-2019

Hitchcock, P., \& Shepherd, T. G. (2013). Zonal-Mean Dynamics of Extended Recoveries from Stratospheric Sudden Warmings. Journal of the Atmospheric Sciences, 70 (2), 688-707. doi: 10.1175/JAS-D-12-0111.1

Hitchcock, P., Shepherd, T. G., \& Manney, G. L. (2013). Statistical Characterization of Arctic Polar-Night Jet Oscillation Events. Journal of Climate, 26 (6), 20962116. doi: 10.1175/JCLI-D-12-00202.1

Hoerling, M. P., Hurrell, J. W., Xu, T., Bates, G. T., \& Phillips, A. S. Twentieth century North Atlantic climate change. Part II: Understanding the effect of Indian Ocean warming. $\quad$ Climate Dynamics, 23(3), 391-405. doi: 10.1007/s00382-004-0433-x

Hoerling, M. P., \& Kumar, A. (2002). Atmospheric Response Patterns Associated with Tropical Forcing. Journal of Climate, 15(16), 2184-2203. doi: 10.1175/ 1520-0442(2002)015〈2184:ARPAWT $\rangle 2.0 . C O ; 2$

Hoskins, B. J., McIntyre, M. E., \& Robertson, A. W. (1985). On the use and significance of isentropic potential vorticity maps. Quarterly Journal of the Royal Meteorological Society, 111(470), 877-946. doi: 10.1002/qj.49711147002

Hu, D., Guan, Z., Tian, W., \& Ren, R. (2018). Recent strengthening of the stratospheric Arctic vortex response to warming in the central North Pacific. Nature Communications, 9(1), 1-10. doi: 10.1038/s41467-018-04138-3

Hurwitz, M. M., Newman, P. A., \& Garfinkel, C. I. (2011). The Arctic vortex in 
March 2011: A dynamical perspective. Atmospheric Chemistry and Physics, 11 (22), 11447-11453. doi: 10.5194/acp-11-11447-2011

Hurwitz, M. M., Newman, P. A., \& Garfinkel, C. I. (2012). On the influence of North Pacific sea surface temperature on the Arctic winter climate. Journal of Geophysical Research: Atmospheres, 117(D19). doi: 10.1029/2012JD017819

Inness, A., Chabrillat, S., Flemming, J., huijnen, v., Langenrock, B., Nicolas, J., ... Inness, A. (2020). The unusual 2020 Arctic ozone hole as seen in the CAMS reanalysis. Earth and Space Science Open Archive. doi: 10.1002/essoar.10503751.1

Ivy, D. J., Solomon, S., Calvo, N., \& Thompson, D. W. J. (2017). Observed connections of Arctic stratospheric ozone extremes to Northern Hemisphere surface climate. Environmental Research Letters, 12(2), $024004 . \quad$ doi: $10.1088 / 1748-9326 / \mathrm{aa} 57 \mathrm{a} 4$

Johnson, N. (2020). Meet ENSO's neighbor, the Indian Ocean Dipole. https://www.climate.gov/news-features/blogs/enso/meet-enso\%E2\%80\%99sneighbor-indian-ocean-dipole.

Juckes, M. N., \& McIntyre, M. E. (1987). A high-resolution one-layer model of breaking planetary waves in the stratosphere. Nature, 328(6131), 590-596. doi: 10.1038/328590a0

Karpechko, A. Y., Hitchcock, P., Peters, D. H. W., \& Schneidereit, A. (2017). Predictability of downward propagation of major sudden stratospheric warmings. Quarterly Journal of the Royal Meteorological Society, 143(704), 1459-1470. doi: $10.1002 /$ qj.3017

Karpechko, A. Y., Perlwitz, J., \& Manzini, E. (2014). A model study of tropospheric impacts of the Arctic ozone depletion 2011. Journal of Geophysical Research: Atmospheres, 119(13), 7999-8014. doi: 10.1002/2013JD021350

Kelleher, M. E., Ayarzagüena, B., \& Screen, J. A. (2020). Interseasonal Connections between the Timing of the Stratospheric Final Warming and Arctic Sea Ice. Journal of Climate, 33(8), 3079-3092. doi: 10.1175/JCLI-D-19-0064.1

Kidston, J., Scaife, A. A., Hardiman, S. C., Mitchell, D. M., Butchart, N., Baldwin, M. P., \& Gray, L. J. (2015). Stratospheric influence on tropospheric jet streams, storm tracks and surface weather. Nature Geoscience, 8(6), 433-440. doi: $10.1038 /$ ngeo2424

Kim, J.-S., Kug, J.-S., Jeong, S.-J., Park, H., \& Schaepman-Strub, G. (2020). Extensive fires in southeastern Siberian permafrost linked to preceding Arctic Oscillation. Science Advances, 6(2), eaax3308. doi: 10.1126/sciadv.aax3308

King, A. D., Butler, A. H., Jucker, M., Earl, N. O., \& Rudeva, I. (2019). Observed Relationships Between Sudden Stratospheric Warmings and European Climate Extremes. Journal of Geophysical Research: Atmospheres, 124(24), 1394313961. doi: 10.1029/2019JD030480

Kobayashi, S., Ota, Y., Harada, Y., Ebita, A., Moriya, M., Onoda, H., .. Takahashi, K. (2015). The JRA-55 Reanalysis: General Specifications and Basic Characteristics. . 2, 93(1), 5-48. doi: 10.2151/jmsj.2015-001

Kodera, K., \& Mukougawa, H. (2017). Eurasian Cold Surges Triggered by the Nonlinear Reflection of Stratospheric Planetary Waves in December 2012. Sola, 13, 140-145. doi: 10.2151/sola.2017-026

Kodera, K., Mukougawa, H., \& Itoh, S. (2008). Tropospheric impact of reflected planetary waves from the stratosphere. Geophysical Research Letters, 35(16). doi: $10.1029 / 2008$ GL034575

Kodera, K., Mukougawa, H., Maury, P., Ueda, M., \& Claud, C. (2016). Absorbing and reflecting sudden stratospheric warming events and their relationship with tropospheric circulation. Journal of Geophysical Research: Atmospheres, 121 (1), 80-94. doi: 10.1002/2015JD023359

Kolstad, E. W., \& Charlton-Perez, A. J. (2011). Observed and simulated precursors of stratospheric polar vortex anomalies in the Northern Hemisphere. Cli- 
mate Dynamics, 37(7), 1443-1456. doi: 10.1007/s00382-010-0919-7

Lawrence, Z. D., \& Manney, G. L. (2018). Characterizing Stratospheric Polar Vortex Variability With Computer Vision Techniques. Journal of Geophysical Research: Atmospheres, 123(3), 1510-1535. doi: 10.1002/2017JD027556

Lawrence, Z. D., Manney, G. L., \& Wargan, K. (2018). Reanalysis intercomparisons of stratospheric polar processing diagnostics. Atmospheric Chemistry and Physics, 18(18), 13547-13579. doi: 10.5194/acp-18-13547-2018

Lee, R. W., Woolnough, S. J., Charlton-Perez, A. J., \& Vitart, F. (2019). $\quad$ ENSO Modulation of MJO Teleconnections to the North Atlantic and Europe. Geophysical Research Letters, 46(22), 13535-13545. doi: 10.1029/2019GL084683

Lee, S. H., Lawrence, Z. D., Butler, A. H., \& Karpechko, A. Y. (2020). Seasonal Forecasts of the Exceptional Northern Hemisphere Winter of 2020. Earth and Space Science Open Archive. doi: 10.1002/essoar.10503976.1

L'Heureux, M. (2019). Seeing Red Across the North Pacific Ocean. https://www.climate.gov/news-features/blogs/enso/seeing-red-across-northpacific-ocean.

Li, S., Perlwitz, J., Hoerling, M. P., \& Chen, X. (2010). Opposite Annular Responses of the Northern and Southern Hemispheres to Indian Ocean Warming. Journal of Climate, 23(13), 3720-3738. doi: 10.1175/2010JCLI3410.1

Limpasuvan, V., Hartmann, D. L., Thompson, D. W. J., Jeev, K., \& Yung, Y. L. (2005). Stratosphere-troposphere evolution during polar vortex intensification. Journal of Geophysical Research: Atmospheres, 110(D24). doi: 10.1029/2005JD006302

Liu, C., Tian, B., Li, K.-F., Manney, G. L., Livesey, N. J., Yung, Y. L., \& Waliser, D. E. (2014). Northern Hemisphere mid-winter vortex-displacement and vortex-split stratospheric sudden warmings: Influence of the Madden-Julian Oscillation and Quasi-Biennial Oscillation. Journal of Geophysical Research: Atmospheres, 119(22), 12,599-12,620. doi: 10.1002/2014JD021876

Lu, H., Hitchman, M. H., Gray, L. J., Anstey, J. A., \& Osprey, S. M. (2020). On the role of Rossby wave breaking in the quasi-biennial modulation of the stratospheric polar vortex during boreal winter. Quarterly Journal of the Royal Meteorological Society, n/a(n/a). doi: 10.1002/qj.3775

Lubis, S. W., Matthes, K., Omrani, N.-E., Harnik, N., \& Wahl, S. (2016). Influence of the Quasi-Biennial Oscillation and Sea Surface Temperature Variability on Downward Wave Coupling in the Northern Hemisphere. Journal of the Atmospheric Sciences, 73(5), 1943-1965. doi: 10.1175/JAS-D-15-0072.1

Lubis, S. W., Silverman, V., Matthes, K., Harnik, N., Omrani, N.-E., \& Wahl, S. (2017). How does downward planetary wave coupling affect polar stratospheric ozone in the Arctic winter stratosphere? Atmospheric Chemistry and Physics, 17(3), 2437-2458. doi: 10.5194/acp-17-2437-2017

Manney, G. L., Froidevaux, L., Santee, M. L., Zurek, R. W., \& Waters, J. W. (1997). MLS observations of Arctic ozone loss in 1996-97. Geophysical Research Letters, 24(22), 2697-2700. doi: 10.1029/97GL52827

Manney, G. L., \& Lawrence, Z. D. (2016). The major stratospheric final warming in 2016: Dispersal of vortex air and termination of Arctic chemical ozone loss. Atmospheric Chemistry and Physics, 16(23), 15371-15396. doi: 10.5194/acp-16-15371-2016

Manney, G. L., Livesey, N. J., Santee, M. L., Froidevaux, L., Lambert, A., Lawrence, Z. D., ... Fuller, R. A. (2020). Record-Low Arctic Stratospheric Ozone in 2020: MLS Observations of Chemical Processes and Comparisons With Previous Extreme Winters. Geophysical Research Letters, 47(16), e2020GL089063. doi: 10.1029/2020GL089063

Manney, G. L., Santee, M. L., Rex, M., Livesey, N. J., Pitts, M. C., Veefkind, P., ... Zinoviev, N. S. (2011). Unprecedented Arctic ozone loss in 2011. Nature, 478(7370), 469-475. doi: 10.1038/nature10556 
Martineau, P., Wright, J. S., Zhu, N., \& Fujiwara, M. (2018). Zonal-mean data set of global atmospheric reanalyses on pressure levels. Earth System Science Data, 10 (4), 1925-1941. doi: 10.5194/essd-10-1925-2018

Matsuno, T. (1970). Vertical Propagation of Stationary Planetary Waves in the Winter Northern Hemisphere. Journal of the Atmospheric Sciences, 27(6), 871-883. doi: 10.1175/1520-0469(1970)027〈0871:VPOSPW $\rangle 2.0 . C O ; 2$

Matthias, V., Dörnbrack, A., \& Stober, G. (2016). The extraordinarily strong and cold polar vortex in the early northern winter 2015/2016. Geophysical Research Letters, 43(23), 12,287-12,294. doi: 10.1002/2016GL071676

Matthias, V., \& Kretschmer, M. (2020). The Influence of Stratospheric Wave Reflection on North American Cold Spells. Monthly Weather Review, 148(4), 16751690. doi: 10.1175/MWR-D-19-0339.1

Newman, P. A., Gleason, J. F., McPeters, R. D., \& Stolarski, R. S. (1997). Anomalously low ozone over the Arctic. Geophysical Research Letters, 24(22), 26892692. doi: 10.1029/97GL52831

Newman, P. A., Nash, E. R., \& Rosenfield, J. E. (2001). What controls the temperature of the Arctic stratosphere during the spring? Journal of Geophysical Research: Atmospheres, 106(D17), 19999-20010. doi: 10.1029/2000JD000061

Newman, P. A., \& Rosenfield, J. E. (1997). Stratospheric thermal damping times. Geophysical Research Letters, 24(4), 433-436. doi: 10.1029/96GL03720

Nie, Y., Scaife, A. A., Ren, H.-L., Comer, R. E., Andrews, M. B., Davis, P., \& Martin, N. (2019). Stratospheric initial conditions provide seasonal predictability of the North Atlantic and Arctic Oscillations. Environmental Research Letters, 14 (3), 034006. doi: 10.1088/1748-9326/ab0385

Orsolini, Y. J., Nishii, K., \& Nakamura, H. (2018). Duration and decay of Arctic stratospheric vortex events in the ECMWF seasonal forecast model. Quarterly Journal of the Royal Meteorological Society, 144(717), 2876-2888. doi: 10 $.1002 /$ qj. 3417

Perlwitz, J., \& Harnik, N. (2003). Observational Evidence of a Stratospheric Influence on the Troposphere by Planetary Wave Reflection. Journal of Climate, 16 (18), 3011-3026. doi: 10.1175/1520-0442(2003)016〈3011:OEOASI $\rangle 2.0 . \mathrm{CO} ; 2$

Petzoldt, K. (1999). The role of dynamics in total ozone deviations from their longterm mean over the Northern Hemisphere. Annales Geophysicae, 17(2), 231241. doi: $10.1007 / \mathrm{s} 00585-999-0231-1$

Polvani, L. M., \& Kushner, P. J. (2002). Tropospheric response to stratospheric perturbations in a relatively simple general circulation model. Geophysical Research Letters, 29(7), 18-1-18-4. doi: 10.1029/2001GL014284

Polvani, L. M., \& Waugh, D. W. (2004). Upward Wave Activity Flux as a Precursor to Extreme Stratospheric Events and Subsequent Anomalous Surface Weather Regimes. Journal of Climate, 17(18), 3548-3554. doi: 10.1175/1520-0442(2004)017〈3548:UWAFAA $>2.0 . \mathrm{CO} ; 2$

Rao, J., Garfinkel, C. I., \& White, I. P. (2020). Predicting the Downward and Surface Influence of the February 2018 and January 2019 Sudden Stratospheric Warming Events in Subseasonal to Seasonal (S2S) Models. Journal of Geophysical Research: Atmospheres, e2019JD031919. doi: 10.1029/2019JD031919@10.1002/(ISSN)2169-8996.BRIDGE1

Scaife, A. A., Karpechko, A. Y., Baldwin, M. P., Brookshaw, A., Butler, A. H., Eade, R., ... Smith, D. (2016). Seasonal winter forecasts and the stratosphere. Atmospheric Science Letters, 17(1), 51-56. doi: 10.1002/asl.598

Schoeberl, M. R., \& Hartmann, D. L. (1991). The Dynamics of the Stratospheric Polar Vortex and Its Relation to Springtime Ozone Depletions. Science, 251(4989), 46-52. doi: 10.1126/science.251.4989.46

Schoeberl, M. R., Lait, L. R., Newman, P. A., \& Rosenfield, J. E. (1992). The structure of the polar vortex. Journal of Geophysical Research: Atmospheres, 97(D8), 7859-7882. doi: 10.1029/91JD02168 
Scott, R. K., Dritschel, D. G., Polvani, L. M., \& Waugh, D. W. (2004). Enhancement of Rossby Wave Breaking by Steep Potential Vorticity Gradients in the Winter Stratosphere. Journal of the Atmospheric Sciences, 61 (8), 904-918. doi: 10.1175/1520-0469(2004)061<0904:EORWBB 2 2.0.CO;2

Shaw, T. A., \& Perlwitz, J. (2013). The Life Cycle of Northern Hemisphere Downward Wave Coupling between the Stratosphere and Troposphere. Journal of Climate, 26 (5), 1745-1763. doi: 10.1175/JCLI-D-12-00251.1

Shaw, T. A., \& Perlwitz, J. (2014). On the Control of the Residual Circulation and Stratospheric Temperatures in the Arctic by Planetary Wave Coupling. Journal of the Atmospheric Sciences, 71(1), 195-206. doi: 10.1175/JAS-D-13-0138 .1

Shaw, T. A., Perlwitz, J., \& Harnik, N. (2010). Downward Wave Coupling between the Stratosphere and Troposphere: The Importance of Meridional Wave Guiding and Comparison with Zonal-Mean Coupling. Journal of Climate, 23(23), 6365-6381. doi: 10.1175/2010JCLI3804.1

Shindell, D. T., \& Schmidt, G. A. (2004). Southern Hemisphere climate response to ozone changes and greenhouse gas increases. Geophysical Research Letters, 31 (18). doi: 10.1029/2004GL020724

Sigmond, M., Scinocca, J. F., Kharin, V. V., \& Shepherd, T. G. (2013). Enhanced seasonal forecast skill following stratospheric sudden warmings. Nature Geoscience, 6(2), 98-102. doi: 10.1038/ngeo1698

Sinnhuber, B.-M., Stiller, G., Ruhnke, R., von Clarmann, T., Kellmann, S., \& Aschmann, J. (2011). Arctic winter 2010/2011 at the brink of an ozone hole. Geophysical Research Letters, 38(24). doi: 10.1029/2011GL049784

Smith, K. L., \& Kushner, P. J. (2012). Linear interference and the initiation of extratropical stratosphere-troposphere interactions. Journal of Geophysical Research: Atmospheres, 117(D13). doi: 10.1029/2012JD017587

Solomon, S. (1999). Stratospheric ozone depletion: A review of concepts and history. Reviews of Geophysics, 37(3), 275-316. doi: 10.1029/1999RG900008

Stone, K. A., Solomon, S., Kinnison, D. E., Baggett, C. F., \& Barnes, E. A. (2019). Prediction of Northern Hemisphere Regional Surface Temperatures Using Stratospheric Ozone Information. Journal of Geophysical Research: Atmospheres, 124(12), 5922-5933. doi: 10.1029/2018JD029626

Strahan, S. E., Douglass, A. R., \& Newman, P. A. (2013). The contributions of chemistry and transport to low arctic ozone in March 2011 derived from Aura MLS observations. Journal of Geophysical Research: Atmospheres, 118(3), 1563-1576. doi: 10.1002/jgrd.50181

Tegtmeier, S., Rex, M., Wohltmann, I., \& Krüger, K. (2008). Relative importance of dynamical and chemical contributions to Arctic wintertime ozone. Geophysical Research Letters, 35(17). doi: 10.1029/2008GL034250

Thompson, D. W. J., \& Solomon, S. (2002). Interpretation of Recent Southern Hemisphere Climate Change. Science, 296(5569), 895-899. doi: 10.1126/ science. 1069270

Thompson, D. W. J., Solomon, S., Kushner, P. J., England, M. H., Grise, K. M., \& Karoly, D. J. (2011). Signatures of the Antarctic ozone hole in Southern Hemisphere surface climate change. Nature Geoscience, 4(11), 741-749. doi: $10.1038 /$ ngeo1296

Thompson, D. W. J., \& Wallace, J. M. (1998). The Arctic oscillation signature in the wintertime geopotential height and temperature fields. Geophysical Research Letters, 25(9), 1297-1300. doi: 10.1029/98GL00950

Thompson, D. W. J., \& Wallace, J. M. (2000). Annular Modes in the Extratropical Circulation. Part I: Month-to-Month Variability. Journal of Climate, 13(5), 1000-1016. doi: 10.1175/1520-0442(2000)013〈1000:AMITEC $\rangle 2.0 . C O ; 2$

Tripathi, O. P., Baldwin, M., Charlton-Perez, A., Charron, M., Eckermann, S. D., Gerber, E., ... Son, S.-W. (2015). The predictability of the extratropical 
stratosphere on monthly time-scales and its impact on the skill of tropospheric forecasts. Quarterly Journal of the Royal Meteorological Society, 141(689), 987-1003. doi: $10.1002 /$ qj.2432

Tripathi, O. P., Charlton-Perez, A., Sigmond, M., \& Vitart, F. (2015). Enhanced long-range forecast skill in boreal winter following stratospheric strong vortex conditions. Environmental Research Letters, 10(10), $104007 . \quad$ doi: 10.1088/1748-9326/10/10/104007

Wang, T., Tian, W., Zhang, J., Xie, F., Zhang, R., Huang, J., \& Hu, D. Connections between Spring Arctic Ozone and the Summer Circulation and Sea Surface Temperatures over the Western North Pacific. Journal of Climate, 33(7), 2907-2923. doi: 10.1175/JCLI-D-19-0292.1

Waugh, D. W., Sobel, A. H., \& Polvani, L. M. (2017). What Is the Polar Vortex and How Does It Influence Weather? Bulletin of the American Meteorological Society, 98(1), 37-44. doi: 10.1175/BAMS-D-15-00212.1

White, I. P., Garfinkel, C. I., Gerber, E. P., Jucker, M., Aquila, V., \& Oman, L. D. (2019). The Downward Influence of Sudden Stratospheric Warmings: Association with Tropospheric Precursors. Journal of Climate, 32(1), 85-108. doi: 10.1175/JCLI-D-18-0053.1

White, I. P., Lu, H., \& Mitchell, N. J. (2016). Seasonal evolution of the QBOinduced wave forcing and circulation anomalies in the northern winter stratosphere. Journal of Geophysical Research: Atmospheres, 121(18), 10,41110,431. doi: $10.1002 / 2015 J D 024507$

WMO. (2014). Scientific Assessment of Ozone Depletion: 2014. Geneva, Switzerland: World Meteorological Organization.

WMO. (2018). Scientific Assessment of Ozone Depletion: 2018. Geneva, Switzerland: World Meteorological Organization.

Wohltmann, I., von der Gathen, P., Lehmann, R., Maturilli, M., Deckelmann, H., Manney, G. L., ... Rex, M. (2020). Near complete local reduction of Arctic stratospheric ozone by severe chemical loss in spring 2020. Earth and Space Science Open Archive. doi: 10.1002/essoar.10503518.1

Xie, F., Ma, X., Li, J., Huang, J., Tian, W., Zhang, J., ... Yang, Y. (2018). $\quad$ An advanced impact of Arctic stratospheric ozone changes on spring precipitation in China. Climate Dynamics, 51(11), 4029-4041. doi: 10.1007/ s00382-018-4402-1

Xie, F., Zhang, J., Huang, Z., Lu, J., Ding, R., \& Sun, C. (2020). An Estimate of the Relative Contributions of Sea Surface Temperature Variations in Various Regions to Stratospheric Change. Journal of Climate, 33(12), 4993-5011. doi: 10.1175/JCLI-D-19-0743.1 